\title{
Practical Guidelines for Perioperative Hypersensitivity Reactions
}

\author{
Laguna $\mathrm{JJ}^{1 \#}$, Archilla $\mathrm{J}^{2}$, Doña ${ }^{3 \#}$, Corominas $\mathrm{M}^{4}$, Gastaminza $\mathrm{G}^{5 \#}$, Mayorga $\mathrm{C}^{3 \#}$, Berjes-Gimeno $\mathrm{P}^{6}$, \\ Tornero $\mathrm{P}^{7}$, Martin $\mathrm{S}^{2}$, Planas $\mathrm{A}^{8}$, Moreno $\mathrm{E}^{* *}$, Torres $\mathrm{MJ}^{3 * \#}$
}

\author{
'Allergy Unit and Allergy-Anesthesia Unit, Hospital Central Cruz Roja, Madrid, Spain \\ ${ }^{2}$ Anesthesia Unit, Hospital Central Cruz Roja, Madrid, Spain \\ ${ }^{3}$ Allergy Unit, Málaga Regional University Hospital-IBIMA, Málaga, Spain \\ ${ }^{4}$ Allergy Unit-Internal Medicine Department, Hospital Universitari de Bellvitge-IDIBELL, L'Hospitalet de Llobregat, Spain \\ ${ }^{5}$ Allergy and Clinic Immunology Department, Clínica Universidad de Navarra, Navarra, Spain \\ ${ }^{6}$ Allergy Unit, University Hospital Ramón y Cajal, Madrid, Spain \\ ${ }^{7}$ Allergy Unit, University Hospital Gregorio Marañón, Madrid, Spain \\ ${ }^{8}$ Anesthesia Unit, University Hospital La Princesa, Madrid, Spain \\ ${ }^{9}$ Allergy Unit, Salamanca University Hospital-IBSAL, Salamanca, Spain \\ *Both authors contributed equally. \\ "Authors who participate in ISCIII RETIC ARADyAL
}

J Investig Allergol Clin Immunol 2018; Vol. 28(3): 216-232

doi: 10.18176/jiaci.0236

\begin{abstract}
Perioperative hypersensitivity reactions constitute a first-line problem for anesthesiologists and allergists. Therefore, hospitals should have a consensus protocol for the diagnosis and management of these reactions. However, this kind of protocol is not present in many hospitals, leading to problems with treatment, reporting of incidents, and subsequent etiological diagnosis. In this document, we present a systematic review of the available scientific evidence and provide general guidelines for the management of acute episodes and for referral of patients with perioperative hypersensitivity reactions to allergy units. Members of the Drug Allergy Committee of the Spanish Society of Allergy and Clinical Immunology (SEAIC) have created this document in collaboration with members of the Spanish Anesthesia Society (SEDAR). A practical algorithm is proposed for the etiologic diagnosis, and recommendations are provided for the management of hypersensitive patients.
\end{abstract}

Key words: Anesthesia. Allergy. Anaphylaxis. Hypersensitivity. Perioperative. Skin tests. Tryptase.

\section{Resumen}

Las reacciones de hipersensibilidad perioperatorias constituyen un problema de primera línea para los anestesiólogos y alergólogos, por lo que es recomendable que los hospitales tengan un protocolo de consenso para el diagnóstico y el tratamiento de estas reacciones. Sin embargo, este tipo de protocolos no está presente en muchos hospitales, lo que conlleva problemas en el tratamiento, la comunicación de incidentes y el posterior diagnóstico etiológico. Este documento ha sido creado por miembros del Comité de Alergia a Medicamentos de la Sociedad Española de Alergia e Inmunología Clínica (SEAIC) en colaboración con miembros de la Sociedad Española de Anestesia (SEDAR). Se ha realizado una revisión sistemática de la evidencia científica disponible y se proporcionan pautas generales para el manejo de episodios agudos y para la derivación de pacientes con reacciones de hipersensibilidad perioperatoria a los Servicios de Alergología. Se propone un algoritmo práctico para el diagnóstico etiológico y se brindan recomendaciones para el manejo de pacientes con reacciones alérgicas perioperatorias.

Palabras clave: Anestesia. Alergia. Anafilaxia. Hipersensibilidad. Periperatorias. Tests cutáneos. Triptasa. 


\section{Introduction}

During the perioperative period, patients are exposed to multiple agents that can induce hypersensitivity reactions, with an estimated incidence of 1 per 10000 anesthesia procedures $[1,2,3]$. However, prospective studies suggest that this is an underestimate and quote incidences of 1:3180 [4] and $1: 1480$ [5]. In a recent prospective Spanish study, the incidence of perioperative reactions was $1: 381$; of these, $48 \%$ were mild, involving only the skin, and 52\% were anaphylaxis [6].

Owing to its low incidence, perioperative anaphylaxis is an unexpected and severe event. This hampers identification and early treatment and partially explains its high mortality (3-10\% of cases) $[1,7]$. Perioperative hypersensitivity reactions constitute a first-line problem for anesthesiologists and allergists, and although it is advisable for hospitals to have a consensus protocol of action for diagnosis and treatment of these reactions [8], few actually do [9-12,13] and no protocols are specifically applicable to the Spanish population. Furthermore, there are no protocols of action for patients with a prior history of perioperative hypersensitivity reactions; these patients must be identified in pre-anesthesia consultations and referred to an allergy specialist for evaluation. This lack of specific protocols can imply a greater potential risk of re-exposure.

The management of perioperative hypersensitivity reactions is extremely complex and should be a combined effort between allergists and anesthesiologists $[14,15]$ based on 2 well-differentiated areas [16,17]: (i) the acute phase of the reaction, which is the anesthesiologist's responsibility [14]; (ii) later diagnosis to confirm the causal agent (if possible) which is the allergist's responsibility. The aim of the present study was to develop clinical guidelines for the management of patients with a hypersensitivity reaction during the perioperative period and for the subsequent allergological diagnosis.

\section{Methodology}

A literature search was performed using key words agreed on by the authors. The search was performed using electronic databases (MEDLINE and PubMed), electronic libraries (Science Direct, OVID), and a database of systematic reviews (Cochrane Library). Publications were selected from between January 1985 and March 2016. The selection took into account the prevalence, pathogenesis, clinical manifestations, diagnosis, and treatment of perioperative hypersensitivity. The key terms used were perioperative anaphylaxis, perianesthetic anaphylaxis, and perioperative hypersensitivity reactions. In addition, the names of drugs commonly involved in perioperative reactions were searched for in combination with the terms skin tests, prick test, intradermal test, in vitro tests, and drug provocation tests. This search revealed 323 publications. Original research articles and systematic reviews were included; nonsystematic reviews, comments, and other types of article were excluded. We also included studies examining incidence, prevalence, natural history, clinical manifestations, pathogenesis, diagnosis, and treatment. Studies not addressing perianesthetic/perioperative hypersensitivity were excluded. Following this review process by the expert panel, 195 publications were finally selected. Moreover, the expert panel evaluated the quality of the evidence and provided grades of recommendation according to the Scottish Intercollegiate Guidelines Network [18]. Wherever evidence was lacking, a consensus was reached among the experts.

\section{Mechanisms of Perioperative Hypersensitivity}

Although clinical presentation and early management are similar, perioperative hypersensitivity reactions may depend on 2 mechanisms: immunological mechanisms (allergic reactions) and nonimmunological mechanisms [19]. IgE-mediated immunological reactions represent $60 \%$ of all reactions and their severity can increase in a subsequent surgery [20-23]. These reactions undergo a sensitization phase, with activation of $\mathrm{T}_{\mathrm{H}} 2$ and $\mathrm{B}$ lymphocytes and production of specific $\operatorname{IgE}$ antibodies that bind to high-affinity receptors of mast cells and basophils. In a second contact with the sensitizing agent and its binding to specific IgE, mediators such as histamine, tryptase, PG2, leukotrienes, thromboxane A2, platelet activating factor, chemokines, and cytokines such as tumor necrosis factor are released, leading to the development of the reaction [24]. It should be noted that in some cases, a reaction can occur upon first contact, which could be due to cross-reactivity with other substances to which the patient is sensitized. On rare occasions, immunological reactions may not be IgE-mediated, as reported for dextrans, which create immunocomplexes with IgG and activate the complement system; in such cases, these reactions are less severe [25].

Although the mechanisms are not well established, it is accepted that nonimmunological reactions are caused by direct stimulation (pharmacological or toxic) of mast cells and basophils, which induces their degranulation [26]; therefore, previous contact with the causative agent is not required [20]. These reactions are generally milder than immunologically mediated ones [7], except for a subgroup of patients, who are over-responders to the histamine released by neuromuscular blocking agents (NMBAs) [3,27,28].

\section{Clinical Symptoms}

The clinical manifestation of anaphylaxis due to anesthesia is similar to that of other forms of anaphylaxis, although it does present specific aspects $[16,29]$. Given that the patient is generally unconscious and covered by surgical drapes and cannot express what is happening, the prodromal symptoms (pruritus, dyspnea, or discomfort) may not be recognized. Instead, the reaction is often first recognized by the anesthesiologist, who notices nonspecific symptoms such as a drop in blood pressure and arterial saturation, difficulty in mechanical ventilation, severe arrhythmias, and cardiovascular collapse [1,30,31]. Consequently, some mild cases may recover spontaneously, meaning that the reaction goes unnoticed. Subsequently, re-exposure can lead to a more severe, potentially life-threatening reaction [4].

Reactions can occur at any time during anesthesia [32], although around $90 \%$ have been shown to occur suddenly during the induction phase after intravenous administration 
of the culprit agent (especially antibiotics, NMBAs, and hypnotic drugs) [32]. Sometimes, reactions can occur with a more delayed latency period, depending on several factors: (i) specific agents, such as dyes [33] and colloids; (ii) route of administration (cutaneous, mucosal, intraperitoneal, or subcutaneous), which delay absorption $[34,35]$ of agents such as latex [9], chlorhexidine, or surgical glues [9,10,36]; (iii) some surgical procedures, such as gynecological procedures, owing to the release of latex particles in utero after the injection of oxytocin [31], and some orthopedic procedures, after the release of the tourniquet used in surgeries with ischemia [37].

Considering the organs involved, cutaneous symptoms, such as erythema, urticaria, and angioedema, are observed in $66 \%-70 \%$ of IgE-mediated reactions and in more than $90 \%$ of non-IgE-mediated reactions [38], with up to $10 \%-20 \%$ of cases not having any cutaneous symptoms $[39,40]$. Cardiovascular symptoms often include hypotension and tachycardia, which may progress rapidly to severe arrhythmia and cardiovascular collapse if they are not treated immediately [31,41-43]. These are the most frequent signs of severe anaphylaxis, and cardiovascular collapse or cardiorespiratory arrest may be the initial presentation symptoms $[40,44]$. In some cases, bradycardia might be the first sign of anaphylaxis; this is problematic, because the reaction could be confused with other, nonallergic anesthesia-related effects, especially if the patient is being treated with $\beta$-blockers. Other rare symptoms include acute coronary events associated with an immediate hypersensitivity reaction, such as Kounis syndrome, which is caused by the release of mediators from the cardiac mast cells $[45,46]$. Respiratory symptoms such as bronchospasm are less frequent and are observed in only around half of all patients [47], particularly those with a prior diagnosis of asthma [47]. The first sign may be an increase in pulmonary resistance or a decrease in oxygen saturation [48]. Other symptoms, such as alteration of coagulation [49], pulmonary edema, and rhabdomyolysis are very rare and are usually related to severe and prolonged anaphylactic shock. These symptoms are usually associated with the coexistence of cardiac disease, $\beta$-blockers, or angiotensin-converting enzyme inhibitors (ACE inhibitors). Given that many clinical symptoms of anaphylaxis reactions can be unspecific and may resemble the symptoms of other problems that can occur during anesthesia [9], it is critical to perform a differential diagnosis (Table 1).
The factors that have been identified as the main contributors to the clinical severity of anaphylaxis $[11,40]$ include the following: (i) age, which is related to lower pulmonary capacity; (ii) prior diseases, especially cardiac or respiratory disease; (iii) systemic mastocytosis or elevated baseline tryptase [50]; (iv) current treatment, which may alter the patient's response to catecholamine treatment, thereby potentially increasing mortality for medicines such as $\beta$-blockers, ACE inhibitors, angiotensin II receptor antagonists, monoaminoxidase inhibitors, tricyclic antidepressants, and serotonin uptake inhibitors; $(v)$ form of administration, with the reaction occurring more rapidly when the drug is administered intravenously; ( $v i$ ) initial presentation of the reaction (such as vascular collapse or cardiorespiratory arrest); (vii) speed of the clinical course (the faster the evolution, the more severe the reaction and the higher the risk of a fatal outcome); (viii) delay in administering epinephrine in the case of severe anaphylaxis [51,52].

Several classification systems have been proposed to evaluate the severity of reactions occurring during anesthesia [11].

\section{Immediate Management of Perioperative Reactions}

The anesthesiologist has a major role to play in both the prevention and the treatment of hypersensitivity reactions.

\subsection{Preventive Measures}

Prior to surgery, the anesthesiologist should evaluate the clinical history to identify previous history of allergy (especially allergy relating to medicines and latex), previous reactions during surgical procedures, and concomitant diseases and their treatments. Any of these factors can affect the development of an allergic reaction during anesthesia and will influence the effect of anesthesia on patient management.

If there is suspicion of latex allergy, the patient must be referred to an allergist for an allergology study prior to surgery. In the case of emergency surgery for a patient with suspected latex allergy, surgery must be performed in a latex-free environment. Similarly, in patients treated for a suspected drug allergy in the emergency department, the suspect drugs should

Table 1. Differential Diagnosis of Perioperative Anaphylaxis

\begin{tabular}{ll}
\hline Pharmacological effect of anesthetic agents & Hypotension, bradycardia \\
\hline Effect of local anesthetics or nerve block & Sympathetic blockade, overdosage, accidental intravascular administration \\
\hline Effect of the surgical technique & Laparoscopy, eye surgery \\
\hline Effect of airway manipulation & Laryngospasm, bronchospasm \\
\hline Complications of surgery & $\begin{array}{l}\text { Pulmonary: Pulmonary edema, pulmonary embolism, amniotic fluid, fat or air } \\
\text { embolism, pneumothorax } \\
\text { Cardiovascular: acute coronary syndrome, tachyarrhythmia, cardiac tamponade } \\
\text { Shock: hemorrhagic, septic, bone cement syndrome }\end{array}$ \\
\hline Underlying disease & $\begin{array}{l}\text { Systemic mastocytosis, hereditary angioedema, malignant hyperthermia, } \\
\text { neuroleptic malignant syndrome, serotonin syndrome, carcinoid, or } \\
\text { pheochromocytoma }\end{array}$ \\
\hline
\end{tabular}


be avoided. Locoregional anesthesia is preferred in these cases. Premedication with corticosteroids and antihistamines should be considered, especially if there is a suspicion of a non-immune-mediated reaction.

\subsection{Management of Reactions}

In the event of a reaction, a step-by-step process must be followed:

\subsubsection{Recognizing the allergic reaction}

The anesthesiologist must evaluate the patient's signs and decide whether they are indicative of anaphylaxis by performing a differential diagnosis (Table 1), establishing the severity of the reaction, and identifying possible culprit agents.

\subsubsection{Treatment of the reaction}

The reaction must be treated immediately, since this will influence the patient's prognosis, especially in severe reactions. Treatment will include general and specific pharmacological treatment depending on the severity of the reaction (Figure 1). The agents used in the treatment of the reaction can be classified as first- and second-line treatments:

(a) First-line treatment

Epinephrine. Anaphylactic reactions involve alterations of vascular permeability, which implies that up to $35 \%-50 \%$

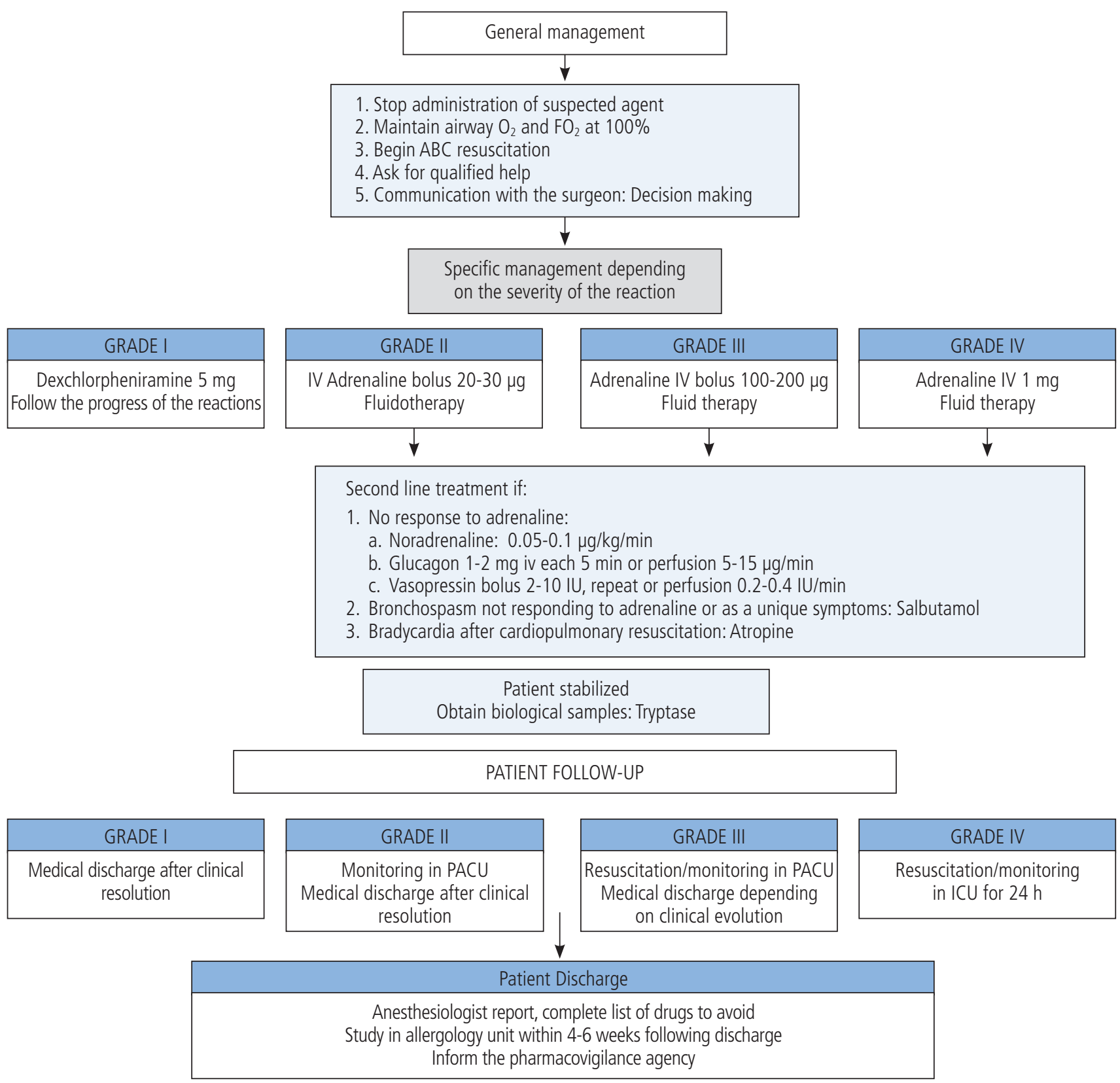

Figure 1. Treatment of perioperative anaphylaxis. ABC indicates airway, breathing, circulation; PACU, postanesthesia care unit; ICU, intensive care unit. 
of intravascular volume can migrate to the interstitial space in 10 minutes. Epinephrine is the drug of choice for treatment of anaphylaxis, and delay in its administration negatively influences the prognosis of severe reactions. There is no contraindication for the use of epinephrine during a reaction, although dosage should be adjusted based on severity in order to avoid severe adverse effects, especially in patients with heart disease.

Vasoactive drugs. In cases where the patient is taking $\beta$-blockers or has heart disease, other vasoactive agents can be given. Norepinephrine, ephedrine, methoxamine, phenylephrine, and dopamine can be administered as an intravenous bolus or continuous infusion [53].

Glucagon. This drug can be also used as a rescue medication in patients who normally receive treatments with $\beta$-blockers and who may not respond to epinephrine. As with norepinephrine vasoactive drugs, patients with heart disease are advised not to take epinephrine [40,54].

Vasopressin. The use of vasopressin in anaphylactic shock is accepted, since it may be consumed during the reaction and no response to vasopressor drugs is observed.

Methylene blue. This drug can be useful owing to its capacity to interfere with the action of nitric oxide in the smooth muscle of vascular walls. It should be administered in combination with epinephrine [55-57].

(b) Second-line treatment

Antihistamines and corticosteroids. These drugs should not replace first-line drugs such as epinephrine for severe reactions, although they can be used in mild reactions (grade I). Corticosteroids are not indicated in the acute phase of the reaction, but may be used to avoid delayed symptoms. Systematic reviews suggest that corticosteroids are not useful for the treatment of anaphylaxis [57,58].

Salbutamol. Salbutamol is indicated in patients who present bronchospasm as a main symptom or if this symptom does not respond to epinephrine.

Atropine. Atropine is restricted to cases of severe bradycardia refractory to epinephrine and/or fluid therapy and in patients treated with $\beta$-blockers, as they can induce cardiac arrest in the early phases of anaphylaxis.

Other treatments. Sugammadex has been proposed as a useful treatment for anaphylaxis symptoms caused by rocuronium $[59,60]$. However, in a recently published case series, sugammadex did not modify the course of the reaction [61]. Magnesium sulphate may be useful in cases of bronchospasm that are refractory to other treatments [62].

\subsubsection{Actions after treatment}

- Obtaining biological samples for diagnosis. Blood should be taken during this stage in order to measure serum tryptase, an indicator of mast cell/basophil degranulation [63]. Other markers such as histamine and methyl-histamine in urine have been used, although these are not recommended in routine practice owing to difficulties in measurement and low sensitivity [64].

- Discharge. In the case of mild reactions (grade I), the patient can be discharged after symptoms resolve. In severe reactions, the patient should be observed for at least 24 hours in a postsurgical recovery unit, in the intensive care unit, or in a regular hospitalization area. Extreme caution must be taken with patients who present severe symptoms and/or do not respond to treatment and/ or experience involvement and/or severe comorbidities, or who have poor access to emergency treatment after discharge.

- Informing the patient. Before the patient is discharged, the anesthesiologist should give him/her a clinical report containing all relevant information about the reaction, including its severity, any treatment administered, and possible causative agents. The patient should be warned that, if anesthesia is needed again prior to the allergology work-up, it should only be for emergency procedures. In addition, the patient must inform the hospital and present the clinical report.

- Referral for allergy evaluation. With respect to a future diagnosis, the anesthesiologist must contact the allergist so that all the information about the event can be properly recorded.

In order to standardize the diagnosis and treatment of anaphylactic reactions, it is advisable to have ready-to-use kits in all areas of anesthesiology departments $[8,15,41]$ including the following: (i) Simple anaphylaxis treatment algorithms, with the dosage of different drugs, route of administration, especially epinephrine, and rescue medication in case of severe/refractory anaphylaxis (Figure 1). (ii) Instructions to obtain biological samples from the patient, including laboratory orders, sample tubes, and instructions on where the samples must be sent (Figure 2). This is crucial for establishing a chronological sequence of the events leading to the reaction. (iii) A standardized data sheet that should be filled in after the reaction has been treated and sent to the relevant allergy department. This sheet should include details of the drugs administered and the temporal sequence of symptom onset. Any treatments administered to resolve the reaction should also be described (Figure 2) [15].

\section{Allergy Evaluation}

The diagnosis of perioperative hypersensitivity reactions is based on the combination of the clinical history, in vitro determinations performed during the acute phase of the reaction, and tests performed once the reaction has resolved. These include skin tests, in vitro tests, and, eventually, drug provocation testing. The diagnostic algorithm is shown in Figure 3.

\subsection{Clinical History}

The clinical history is the first step for establishing a diagnosis, although all the information comes from the anesthesiologist's report (grade of recommendation, D) $[9,12,65]$. It is important to evaluate various aspects, as follows: clinical signs and symptoms of the reaction; grade of severity [11]; drugs administered for treating the reaction and the time needed to resolve the reaction; personal history of allergy, including atopy and allergy to other drugs; risk factors, such as age; underlying diseases and treatments, such as $\beta$-blockers and ACE inhibitors; and all possible drugs and 


\begin{tabular}{|c|c|c|c|c|c|c|}
\hline \multicolumn{4}{|c|}{ Perioperative anaphylaxis } & \multirow{2}{*}{$\begin{array}{l}\text { Drug (pre-anesthesia } \\
\text { and anesthesia) }\end{array}$} & \multirow[t]{2}{*}{ Dosage } & \multirow[t]{2}{*}{ Time } \\
\hline \multirow{2}{*}{\multicolumn{4}{|c|}{\begin{tabular}{l|l} 
Identification: ............................................. & Identification label \\
First name.
\end{tabular}}} & & & \\
\hline & & & & \multicolumn{3}{|c|}{ 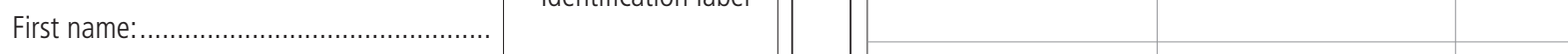 } \\
\hline \multicolumn{7}{|l|}{ Surname: ............... } \\
\hline \multicolumn{7}{|l|}{ Address: ..... } \\
\hline \multicolumn{7}{|c|}{ Phone: } \\
\hline \multicolumn{7}{|c|}{ Date of surgery:...................................... } \\
\hline \multicolumn{7}{|c|}{ 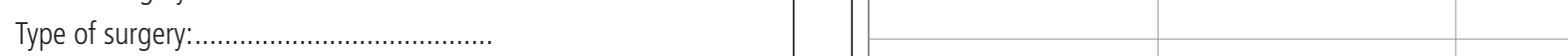 } \\
\hline \multicolumn{7}{|c|}{ 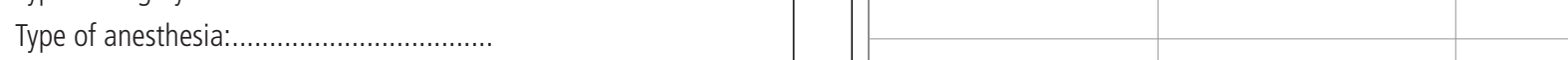 } \\
\hline \multicolumn{7}{|l|}{ Time surgery started: } \\
\hline \multicolumn{7}{|c|}{ 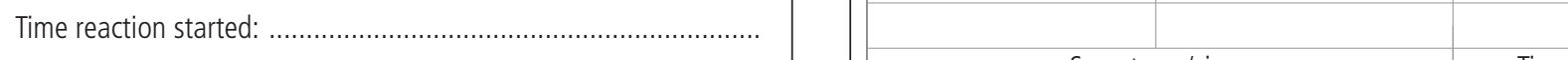 } \\
\hline \multirow{2}{*}{\multicolumn{4}{|c|}{ 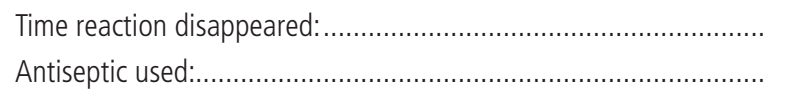 }} & \multicolumn{2}{|c|}{ Symptoms/signs } & Time \\
\hline & & & & Hypotension & Diastolic pressure $(\mathrm{mmHg})$ : & \\
\hline & & & & Tachycardia & $\square$ & \\
\hline \multirow{4}{*}{\multicolumn{4}{|c|}{ TRYPTASE }} & Bradycardia & $\square$ & \\
\hline & & & & Bronchospasm & $\square$ & \\
\hline & & & & Cyanosis/Desaturation & Saturation (\%): & \\
\hline & & & & Angioedema & $\square$ & \\
\hline \multirow{3}{*}{ Tryptase } & \multirow{3}{*}{\multicolumn{2}{|c|}{ Sample ${ }^{\mathrm{a}}$}} & \multirow{6}{*}{$\begin{array}{l}\text { Ref. No. } \\
\text { Serum }\end{array}$} & Urticaria & $\square$ & \\
\hline & & & & Arrhythmia & $\square$ & \\
\hline & & & & Erythema & $\square$ & \\
\hline 1 Initial $^{\mathrm{b}}$ & YES & NC & & Pruritus & $\square$ & \\
\hline 2 After 2 hours & YES & $\mathrm{NC}$ & & Other (Specify) & $\square$ & \\
\hline 3 After 24 hours & YES & $\mathrm{NC}$ & & & & \\
\hline \multirow{4}{*}{\multicolumn{4}{|c|}{$\begin{array}{l}\text { aMark with a cross as appropriate. } \\
\text { bBlood sampling (serum or plasma) for mast cell tryptase immediately } \\
\text { after initial treatment. }\end{array}$}} & \multicolumn{2}{|c|}{ Treatment } & Time \\
\hline & & & & Adrenaline & $\square$ & \\
\hline & & & & Corticosteroids & $\square$ & \\
\hline & & & & Antihistamines & $\square$ & \\
\hline \multirow{4}{*}{\multicolumn{4}{|c|}{$\begin{array}{l}\text { Send this document to the Allergy Service with: } \\
\text { - Copy of the anesthesia chart } \\
\text { - Copy of the anesthesia notes } \\
\text { - Treatment sheet in the reanimation area }\end{array}$}} & Anti- $\mathrm{H}_{2}$ & $\square$ & \\
\hline & & & & Other vasoactive drugs & $\square$ & \\
\hline & & & & Other (specify) & $\square$ & \\
\hline & & & & & & \\
\hline
\end{tabular}

Figure 2. Data collection document and instructions.

agents used during the perioperative period, alongside details on their temporal sequence of administration. The agents most frequently involved include the following:

\subsubsection{Drugs}

Antibiotics. Antibiotics are usually administered before the induction phase [12] and constitute the most common cause of perioperative anaphylaxis in Spain [5]. It would be useful to separate the administration of prophylactic antibiotic therapy and anesthetic induction in order to identify and treat the reaction as early as possible. B-Lactams, especially cephalosporins [5], are responsible for $70 \%$ of reactions due to antibiotics [20], with cefazolin being the most frequent causal agent in Spain [66]. Vancomycin is the second most common antibiotic involved, although reactions are almost always due to a nonimmunological mechanism [67]. Quinolones are the third most important group, with a high incidence [68]. Finally, other potentially important antibiotics include gentamicin, metronidazole, and tobramycin, which are mainly used in abdominal surgery [69].

NMBAs. In some studies, NMBAs are the agents most frequently involved in reactions [20,70,71]. Diagnosis is complex, as reactions can sometimes appear in patients receiving these drugs for the first time. This could be explained by the existence of cross-reactivity with other substances 


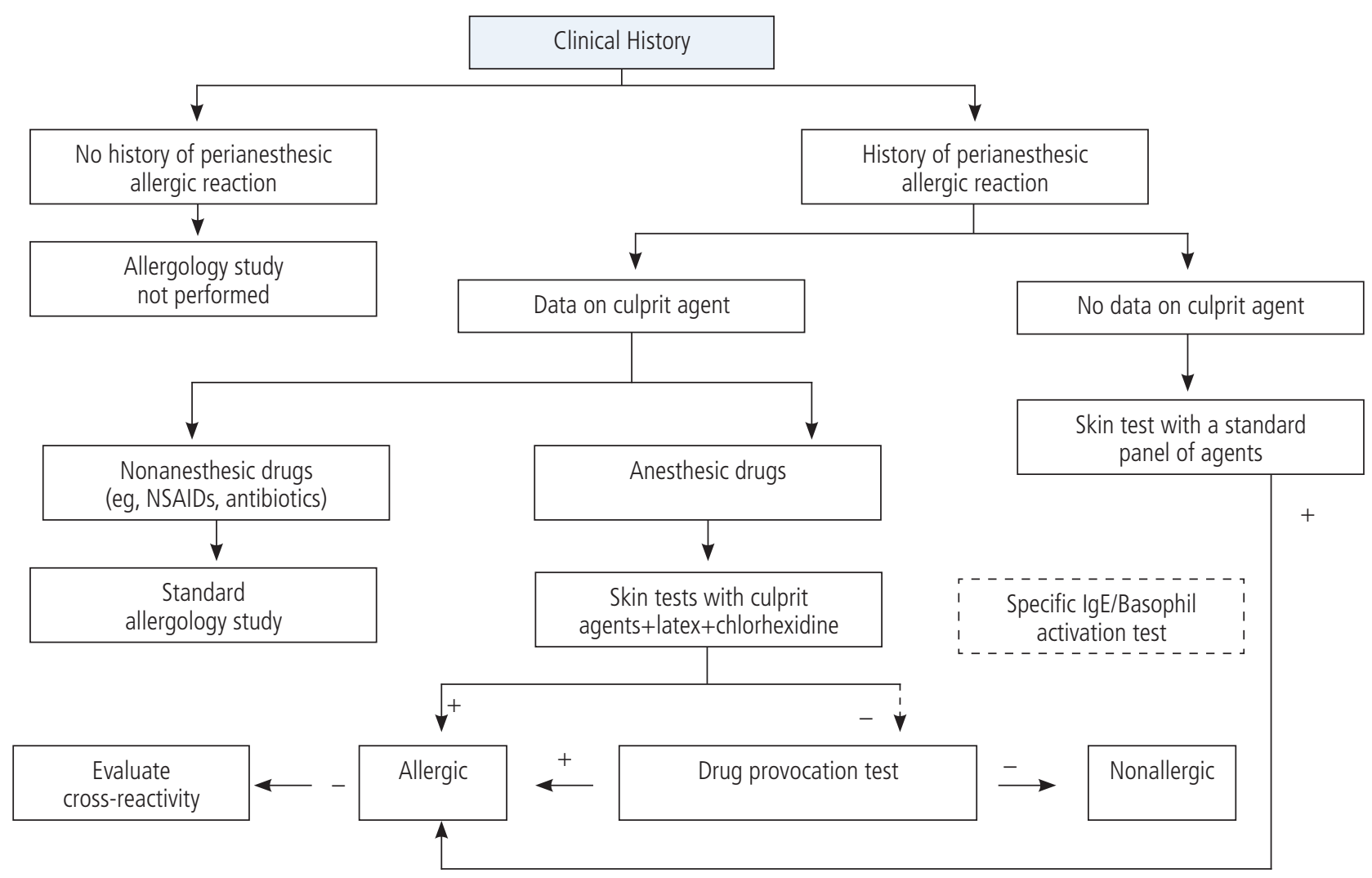

Figure 3. Algorithm for diagnosing perioperative hypersensitivity reactions. NSAID indicates nonsteroidal anti-inflammatory drug.

containing tertiary or quaternary ammonium groups such as cosmetics, foods, industrial material, and disinfectants [72]. Although this hypothesis has not been proven, it was recently shown that contact with quaternary ammonium in hairdressing students is associated with an increase in the incidence of $\operatorname{IgE}$ antibodies against NMBAs [22]. It was also shown that the use of pholcodine, which is present in some cough medicines, is related to an increase in the incidence of NMBA allergy, thus possibly explaining differences in incidence between countries, as the consumption of such medicines is variable [37]. Finally, diagnosis is complicated by the fact that all NMBAs are histamine-releasing drugs, especially benzylisoquinoline derivatives (d-tubocurarine, atracurium, and mivacurium) [26].

Sugammadex. Sugammadex is a modified gamma cyclodextrin that acts as a blocking agent of the aminosteroid NMBAs, especially rocuronium. It can induce IgE-mediated reactions [73-76].

Hypnotics. These include 2 groups of chemically unrelated drugs (barbiturates and nonbarbiturates). Drugs from the barbiturate group are used infrequently nowadays. Thiopental is the most highly consumed, and although IgE-mediated reactions have been reported, most are induced by nonspecific histamine release [77].

The nonbarbiturate group includes propofol, ketamine, etomidate, benzodiazepines, and inhaled anesthetics. Propofol is the cause of $2.3 \%-2.6 \%$ of perioperative anaphylactic reactions $[20,78]$, most of which are IgE-mediated; the antigenic determinant is the 2-isopropyl group of the molecule (2,3 diisopropylphenol). Soybean oil and egg-derived lecithin are both used during its formulation, and although it has been suggested that patients with severe anaphylaxis to egg and/or soy should undergo an allergology work-up or use alternative treatment [79], these drugs seem to be safe in most patients. One study of 99 patients with positive specific IgE to egg, soya, or peanut (only $44 \%$ had immediate clinical symptoms) found that none had an allergic reaction following exposure to propofol [78]. In a Spanish study of 52 adult patients with eosinophilic esophagitis sensitized to egg, soy, or peanut, none of the patients who received propofol before an endoscopy procedure reacted to the drug [80]. In fact, according to our literature search, no reactions to propofol have been documented for soy- or egg-allergic patients. Moreover, prick testing with soya oil and propofol has always yielded negative results, indicating that there are no reasons to contraindicate its use $[79,80]$.

Hypersensitivity reactions to benzodiazepines are extremely rare; midazolam was the most frequent etiological agent in the few cases that have been reported [7,20]. Reactions to etomidate and ketamine are also rare; in fact etomidate is considered one of the safest drugs in anesthesia in terms of allergic reactions $[7,81]$.

Opioids. Reactions are rare, and although there have been some IgE-mediated reactions, most are due to nonspecific histamine release [82-85]. Semisynthetic opioids such as 
fentanyl, alfentanil, remifentanil, and sufentanil do not cause histamine release by themselves. Morphine derivatives are chemically different from phenylpiperidines, and there is no cross-reactivity between them [82-86]. While infrequent, allergic reactions to opioids are an important problem because these drugs are essential for anesthesia and it is difficult to find a safe alternative.

Nonsteroidal anti-inflammatory drugs (NSAIDs). NSAIDs are responsible for a high number of perioperative reactions $[5,20]$. In general, nonimmunological reactions due to COX-1 inhibition are more common [29]. In some cases, the underlying mechanism can be immunological, most often due to pyrazolones, followed by diclofenac, although again, specific studies relating to incidence in perioperative reactions are needed [87].

Local anesthetics. Although widely used, local anesthetics rarely induce adverse effects related to overdose or accidental intravascular administration [88]. In exceptional cases, they induce hypersensitivity reactions, which are mainly associated with the amide group [39,89].

Other drugs. There have been anecdotal reports of cases of anaphylaxis induced by heparins [39], tranexamic acid [90], uterotonic drugs [91,92], atropine [93], and neostigmine [93].

\subsubsection{High-molecular-weight agents}

Colloids. These can cause up to $4 \%$ of perioperative anaphylactic reactions, usually appearing 20-30 minutes after initiation of the infusion [1]. Gelatins are responsible for most reactions $(95 \%)$, followed by dextrans, and although both can induce nonspecific histamine release, IgE-mediated reactions due to gelatins and IgG-mediated reactions due to complement activation by dextran have been reported $[39,94]$. Gelatins can be a cause of anaphylaxis in patients sensitized to the carbohydrate epitope $\alpha$-gal [95]. The incidence of reactions is much lower for albumin and exceptional for hydroxyethyl starch [96,97].

Protamine. Hypersensitivity reactions mediated by $\mathrm{IgG}$, IgE, complement activation, and nonspecific histamine release have been reported $[17,98]$. Patients who have been previously exposed to this drug are at a higher risk of developing a reaction, regardless of whether the drug was given for blocking the effect of heparin or combined with insulin. Protamine is derived from fish sperm; however there is no increased risk for patients undergoing vasectomy or those allergic to fish [58]. It is important to be aware that rapid protamine infusion can induce hypotension.

Aprotinin. Aprotinin is a bovine-derived protease inhibitor used via the parenteral route as a fibrinolysis inhibitor or topically as a surgical glue [17]. The incidence of reactions in cardiac surgery is $0.5 \%$, although this can increase to $2.5 \%-2.8 \%$ in patients who have previously undergone multiple surgeries $[99,100]$, especially during the previous 6 months [31]. Perioperative anaphylaxis has also occurred upon the first parenteral administration in patients who had previously received topical aprotinin [17].

Hyaluronidase. Hyaluronidase is a bovine or ovine enzyme that degrades hyaluronic acid and can be used as a drug or fluid adjuvant. Both immediate reactions [101] and delayed reactions [102] have been reported during ocular surgery and epidural injection.

\subsubsection{Antiseptics and sterilizers}

Antiseptics. There are significant geographical differences with respect to the incidence of chlorhexidine-induced perioperative anaphylaxis. Reactions have been reported to be frequent in the UK and Scandinavia [71,103,104], with chlorhexidine accounting for $8.7 \%-9.6 \%$ of cases of perioperative anaphylaxis; however, such reactions were found to be relatively rare in France [22], perhaps because of the limited use of chlorhexidine in the operating room. The mechanism is IgE-mediated, and although reactions usually appear 20-30 minutes after administration, onset and severity depend on the administration route, with cutaneous application rarely causing severe reactions [36]. Nevertheless, when it is applied to mucous membranes (urinary catheters or oral cavity washes) or by parenteral routes (venous catheters or surgical meshes), the onset of clinical symptoms can be faster and more severe $[36,104,105]$. The appearance of anaphylaxis induced by povidone is unusual, and it is noteworthy that no cross-reactivity with iodinated contrast media has been reported [12,70].

Sterilizers. Ethylene oxide is a gas used for sterilizing multiple medical devices. Reactions have mainly been described in dialyzed patients and in those with spina bifida and are extremely rare during perioperative reactions [1]. Administration of anesthesia without ethylene oxide is a challenge for the anesthesiologist, because in some cases it cannot be substituted. The case is similar for some intraarterial catheters, pump infusion systems, and intratracheal tubes.

\subsubsection{Dyes}

Isosulfan blue, its isomer patent blue $\mathrm{V}$, and methylene blue are used for mapping sentinel lymph nodes in patients with breast cancer or melanoma. They are all capable of inducing hypersensitivity reactions, and the incidence of such reactions has been on the increase in the last decade owing to a rise in their intraoperative use [106]. Isosulfan blue and patent blue $\mathrm{V}$ can induce anaphylaxis in up to $1 \%$ of individuals who receive it, with reactions usually appearing 10-30 minutes after administration [107]. The typical reaction involves the appearance of blue wheals [108], although severe reactions with shock can appear in some cases. In most cases, there has been no previous medical exposure to these dyes, and it is thought that sensitization occurs through exposure to cosmetics or other objects. Anaphylaxis induced by methylene blue is less frequent, and this agent can be an alternative in patients sensitized to isosulfan blue [107], although cross-reactivity has been described in a few cases [109].

\subsubsection{Latex}

A decrease in the number of reactions to latex has been reported in several countries as a result of the reduction in latex exposure and sensitization by decreasing the protein content and stopping the use of powdered gloves [110,111]. The absorption of latex allergens usually occurs through the skin and mucous membranes, and although reactions can appear at any time during surgery, onset of symptoms is usually delayed. Abdominal, gynecological, and orthopedic surgery are usually 
associated with an increased risk, and incidence is likely to be higher in the case of atopic patients, health system personnel, workers exposed to latex, patients undergoing multiple surgeries, women undergoing in vitro fertilization, children with urogenital malformation or spina bifida, and those with a history of perioperative anaphylaxis [112,113].

\subsection{Skin Tests}

Skin tests are the initial diagnostic approach. Interpretation of the results depends on clinical symptoms (grade of recommendation, B). In most cases, the skin prick test will be

Table 2. Recommended Concentrations for Skin Tests: Skin Prick Tests and Intradermal Tests

\begin{tabular}{|c|c|c|}
\hline & SPT Concentration & IDT Concentration \\
\hline \multicolumn{3}{|l|}{ NMBAs } \\
\hline Atracurium & $1 \mathrm{mg} / \mathrm{mL}$ & $0.01 \mathrm{mg} / \mathrm{mL}$ \\
\hline Cisatracurium & $2 \mathrm{mg} / \mathrm{mL}$ & $0.02 \mathrm{mg} / \mathrm{mL}$ \\
\hline Mivacurium & $0.2 \mathrm{mg} / \mathrm{mL}$ & $0.002 \mathrm{mg} / \mathrm{mL}$ \\
\hline Pancuronium & $2 \mathrm{mg} / \mathrm{mL}$ & $0.2 \mathrm{mg} / \mathrm{mL}$ \\
\hline Rocuronium & $10 \mathrm{mg} / \mathrm{mL}$ & $0.05 \mathrm{mg} / \mathrm{mL}$ \\
\hline Vecuronium & $4 \mathrm{mg} / \mathrm{mL}$ & $0.4 \mathrm{mg} / \mathrm{mL}$ \\
\hline Suxamethonium & $10 \mathrm{mg} / \mathrm{mL}$ & $0.1 \mathrm{mg} / \mathrm{mL}$ \\
\hline \multicolumn{3}{|l|}{ Hypnotics } \\
\hline Etomidate & $2 \mathrm{mg} / \mathrm{mL}$ & $0.2 \mathrm{mg} / \mathrm{mL}$ \\
\hline Ketamine & $10 \mathrm{mg} / \mathrm{mL}$ & $1 \mathrm{mg} / \mathrm{mL}$ \\
\hline Propofol & $10 \mathrm{mg} / \mathrm{mL}$ & $1 \mathrm{mg} / \mathrm{mL}$ \\
\hline Thiopental & $25 \mathrm{mg} / \mathrm{mL}$ & $2.5 \mathrm{mg} / \mathrm{mL}$ \\
\hline Midazolam & $5 \mathrm{mg} / \mathrm{mL}$ & $0.5 \mathrm{mg} / \mathrm{mL}$ \\
\hline \multicolumn{3}{|l|}{ Opioids } \\
\hline Alfentanil & $0.5 \mathrm{mg} / \mathrm{mL}$ & $0.05 \mathrm{mg} / \mathrm{mL}$ \\
\hline Fentanyl & $0.05 \mathrm{mg} / \mathrm{mL}$ & $0.005 \mathrm{mg} / \mathrm{mL}$ \\
\hline Remifentanil & $0.05 \mathrm{mg} / \mathrm{mL}$ & $0.005 \mathrm{mg} / \mathrm{mL}$ \\
\hline Sufentanil & $0.05 \mathrm{mg} / \mathrm{mL}$ & $0.0005 \mathrm{mg} / \mathrm{mL}$ \\
\hline Morphine & $1 \mathrm{mg} / \mathrm{mL}$ & $0.01 \mathrm{mg} / \mathrm{mL}$ \\
\hline Sugammadex & Undiluted & $1 / 100$ \\
\hline \multicolumn{3}{|l|}{$\beta$-lactams } \\
\hline BPO-OL & 0.04 & 0.04 \\
\hline $\mathrm{MD}$ & 0.5 & 0.5 \\
\hline Amoxicillin & $20 \mathrm{mg} / \mathrm{mL}$ & $20 \mathrm{mg} / \mathrm{mL}$ \\
\hline Cephalosporins & $20 \mathrm{mg} / \mathrm{mL}$ & $2 \mathrm{mg} / \mathrm{mL}$ \\
\hline Local anesthetics & Undiluted & $1 / 10$ \\
\hline Heparins & Undiluted & $1 / 10$ \\
\hline Tranexamic acid & Undiluted & $1 / 10$ \\
\hline Protamine & Undiluted & $1 / 1000-1 / 10000$ \\
\hline Aprotinin & $1 / 5$ & $1 / 500$ \\
\hline Hyaluronidase & Undiluted & $1 / 10$ \\
\hline \multicolumn{3}{|l|}{ Antiseptics } \\
\hline Chlorhexidine & $5 \mathrm{mg} / \mathrm{mL}$ & $0.002 \mathrm{mg} / \mathrm{mL}$ \\
\hline \multicolumn{3}{|l|}{ Dyes } \\
\hline Patent blue & Undiluted & $1 / 10$ \\
\hline Methylene blue & Undiluted & $1 / 10$ \\
\hline
\end{tabular}

Abbreviations: BPO-OL, benzylpenicilloyl; IDT, intradermal test; MD, minor determinant; NMBA, neuromuscular blocking agent; SPT, skin prick test. followed by an intradermal test. A skin prick test is considered positive when the mean wheal diameter is larger than $3 \mathrm{~mm}$ and surrounded by erythema and when the saline control is negative [87]. An intradermal test is considered positive when there is an increase greater than $3 \mathrm{~mm}$ of the initial wheal made by injection of the drug [87] (grade of recommendation, C). Skin testing should be performed within 4-6 weeks after the reaction. Sensitivity decreases over time; this decrease is faster for $\beta$-lactams than for NMBAs (grade of recommendation, D) $[114,115]$.

The optimal concentration for skin tests is not clearly defined in all cases for drugs that can induce nonspecific histamine release $[116,117]$. Therefore, false-positive results can occur with drugs such as NMBAs (mivacurium, atracurium, cisatracurium, and succinylcholine), thiopental, opioids, and some antibiotics such as vancomycin and quinolones. A detailed investigation to determine the maximal nonreactive concentration for NMBAs in healthy individuals has been performed [118]. The concentrations recommended as nonirritant are shown in Table $2[31,119]$.

Skin testing with NMBAs is considered to be highly sensitive $(>95 \%)$ and specific (96-98\%) and therefore mandatory for diagnosis and evaluating cross-reactivity, although this observation needs to be confirmed in other populations (grade of recommendation, C) [120]. Crossreactivity among NMBAs has been reported, thus making it necessary to test other NMBAs when looking for a safe alternative (grade of recommendation, C) [9,12,121]. In addition, skin prick tests with latex show high sensitivity and specificity (grade of recommendation, B) (93\% and $100 \%$, respectively) [122]. Chlorhexidine is also highly sensitive and specific: $95 \%$ and $97 \%$, respectively, for skin prick tests and $68 \%$ to $100 \%$ for intradermal tests (grade of recommendation, B) [103].

Skin testing can also be useful for diagnosing allergic reactions to antibiotics. However, except for $\beta$-lactams, in which sensitivity has been estimated to be $70 \%$ [123], sensitivity and specificity are not well established (grade of recommendation, B) [119]. In the case of NSAIDs, skin testing is only recommended for reactions to pyrazolones (grade of recommendation, C) $[87,124]$. Skin testing can be used to diagnose hypersensitivity reactions to hypnotic drugs [125], sugammadex [126], local anesthetics [89], and dyes [127] (grade of recommendation, C). The value of skin testing with opioids such as morphine for detection of perioperative reactions is unclear owing to their capacity to induce nonspecific histamine release (grade of recommendation, C) [116]. Given the mechanisms of reactions to dextrans (immune complexmediated or complement activation), the value of skin tests is not established (grade of recommendation, D) [12].

There is some controversy over when to perform skin tests and which agents to use. The allergist has a key role here. Various scenarios can occur in clinical practice. First, patients have no previous clinical history of perioperative allergic reaction. In these cases there is no indication to perform skin tests (grade of recommendation, B) $[12,118,128]$. Second, patients may have a previous history of reactions, with detailed information on reaction kinetics and drugs and agents administered. In these cases, skin testing is mandatory for all the agents administered plus latex [129] and chlorhexidine 
Table 3. Agents and Drugs Panel to Use in Skin Testing in Those Patients Where the Possible Culprits Are not Identified by the Clinical History

\begin{tabular}{lcc}
\hline Muscle relaxants & Hypnotics & Opioids \\
\hline Atracurium & Propofol & Alfentanil \\
Cisatracurium & Etomidate & Fentanyl \\
Mivacurium & Ketamine & Remifentanil \\
Pancuronium & Thiopental & Sufentanil \\
Rocuronium & Midazolam & Morphine \\
Vecuronium & \\
Suxamethonium & & \\
\hline & Chlorhexidine \\
\hline
\end{tabular}

$[71,103,104,130]$ (grade of recommendation, C), although results may not be reliable until 4-6 weeks after the initial reaction [131]. Third, patients may have experienced reactions but provide no clear information on the episode - the most complex scenario-especially when there is a long interval between the reaction and the study. In this case, the type of surgery and anesthesia and the severity of the reaction can help when choosing the agents to test. Nevertheless, skin testing should be performed with all the essential agents needed for anesthesia, including a muscle relaxant derivative and an opioid (grade of recommendation, D) (Table 3).

\subsection{In Vitro Tests}

In vitro tests can be performed during the acute phase of the reaction or once it has subsided. The former help to understand the mechanisms involved in and the latter to identify the culprit agent (grade of recommendation, C).

\subsubsection{Acute phase of the reaction}

In this case, tests are mainly based on the determination of histamine and tryptase.

Determination of plasma histamine. Levels of histamine usually increase in the first 5-10 minutes after symptom onset; their half-life is $15-20$ minutes, which is why blood samples need to be taken during the first 15-30 minutes of the reaction $[11,132]$. It is important to maintain the tube at $4^{\circ} \mathrm{C}$ until processing to avoid nonspecific release due to cellular lysis. This determination is not sufficiently standardized for diagnostic use (grade of recommendation, C).

Determination of serum tryptase. Tryptase stays in the blood for hours, with maximum levels appearing after 1-2 hours and remaining high for a further 4-6 hours. This means that blood samples can be obtained between 30 minutes and 6 hours after the reaction. Moreover, the samples are less sensitive to environmental conditions, as determination is performed in serum. Various cut-offs have been considered, ranging from $8.23 \mu \mathrm{g} / \mathrm{L}$ to $11.4 \mu \mathrm{g} / \mathrm{L}$ [94-96], although the best criterion is a 2 -fold or $2+1.2 \times$ increase above baseline levels (grade of recommendation, B) [63,133]. Tryptase levels are especially high in more severe reactions $[134,135]$. However, since the measurement of tryptase also accounts
Table 4. Available In Vitro Methods for Identifying the Culprit Agent Involved in Perioperative Reactions

\begin{tabular}{lcc}
\hline Drug & ImmunoCAP & BAT \\
\hline Barbiturates & $\mathrm{X}^{\mathrm{a}}$ & $\mathrm{X}$ \\
Propofol & $\mathrm{X}^{\mathrm{a}}$ & $\mathrm{X}$ \\
Local anesthetics & $\mathrm{X}^{\mathrm{a}}$ & $\mathrm{X}$ \\
Neuromuscular blocking agents & $\mathrm{X}^{\mathrm{b}}$ & $\mathrm{X}$ \\
Latex & $\mathrm{X}$ & $\mathrm{X}$ \\
Opioids & $\mathrm{X}^{\mathrm{c}}$ & $\mathrm{X}$ \\
Atropine & & $\mathrm{X}$ \\
Protamine & & $\mathrm{X}$ \\
Gelatins & & $\mathrm{X}$ \\
Chlorhexidine & $\mathrm{X}$ & \\
Ethylene Oxide & $\mathrm{X}$ & $\mathrm{X}$ \\
\hline
\end{tabular}

Abbreviation: BAT, basophil activation test.

aResearch: thiopental, mepivacaine, propofol, rocuronium, paracetamol, diclofenac.

${ }^{\mathrm{b}}$ Available: suxamethonium.

'Available: pholcodine and morphine.

for a high frequency of false negatives and a low predictive value $(54 \%)$, a normal tryptase value does not rule out real anaphylaxis [93]. Although tryptase is more often increased than histamine, the former suggests an IgE-mediated reaction $[30,134]$. Furthermore, tryptase can be determined in deceased patients $[11,30,136]$.

\subsubsection{Resolution phase}

In vitro methods are further described in Table 4.

Specific IgE determination. This method is useful when combined with skin test results, but not in isolation (grade of recommendation, B). The most widely available method is ImmunoCAP (Thermo Fisher), which can be used with latex, suxamethonium, morphine, pholcodine, bovine gelatine, protamine, chlorhexidine, thiopental, ethylene oxide, and some antibiotics. It is also possible to determine specific $\mathrm{IgE}$ to quaternary ammonium using the same method, and this can be used as a marker of sensitization to NMBAs and opioids. As this determination is positive in $3 \%-10 \%$ of nonallergic patients, results should be interpreted with caution [137].

Basophil activation test (BAT). BAT is useful when confirming skin test results for diagnosing or assessing crossreactivity [138] (grade of recommendation, B). Some authors have obtained promising results in reactions induced by muscle relaxants; consequently, the test is recommended for routine analysis [139]. Moreover, some authors consider that performing the BAT with muscle relaxants is useful for diagnosis, even in patients with negative skin test results, and that it can be used for the identification of safe alternatives $[137,139,140]$. However, identification of safe alternatives based on BAT only should be regarded with caution, taking into account that only small series with BAT have been reported.

Other determinations. Histamine and sulphidoleukotriene release assays have limited utility (grade of recommendation, C) $[141,142]$. 


\subsection{Drug Provocation Tests}

Drug provocation tests are considered the gold standard for diagnosing drug hypersensitivity (grade of recommendation, C) and consist of the administration of increasing doses of the drug at 30 minute intervals in a single-blinded and placebo-controlled manner until the therapeutic dose is reached or a reaction occurs $[143,144]$. Many of the drugs administered during the perioperative period, such as antibiotics and NSAIDs, are studied following regular procedures and are beyond the scope of this review. However, DPT with perioperative drugs has several added limitations, and there is no consensus procedure (grade of recommendation, C) $[10,145,146]$. The goal is to reach a total dose of the drug needed for induction of anesthesia (propofol, etomidate, ketamine) or to be administered during the anesthetic procedure (opioids, midazolam). This dose is not standard for all patients and depends on body weight and underlying diseases (Table 5) [147,148].

Although some of these agents can be administered in allergology units, many require coordination with the anesthesiology unit. Cardiovascular and respiratory monitoring is mandatory.

- Drugs administered in the allergy unit. It is generally preferable to use the oral and subcutaneous routes (grade of recommendation, D), with close monitoring of the patient. Every attempt should be made to avoid high-risk patients such as older patients or patients with comorbidities; for example, drug exposure might provoke reactions that are hard to control [143]. Among the opioids, morphine, pethidine, and fentanyl can generally be administered without major adverse effects, and if they do appear, they can be reversed with naloxone at an initial dose of $0.4 \mathrm{mg}$ and repeated every 2-3 minutes until a response is obtained or a maximum dose of $10 \mathrm{mg}$ is achieved [149]. Benzodiazepine is quite safe, and its sedative effects can be reversed with flumazenil, starting with a dose of $0.2 \mathrm{mg}$, and if necessary, repeating the dose of $0.2 \mathrm{mg}$ each minute until a maximum dose of $1 \mathrm{mg}$ is reached [149].

- Drugs administered in the surgery area. This approach is only indicated when there are no alternatives to administering anesthesia. A risk-benefit analysis should be performed, and administration should be intravenous (grade of recommendation, D) [3,10]. It should be performed in a setting with adequate cardiovascular and respiratory monitoring and in the presence of well-trained personnel to manage cardiovascular events (hypotension, bradycardia), respiratory events (depression), and hypersensitivity reactions (grade of recommendation, $\mathrm{C}$ ). The most adequate setting is the operating room or the postanesthesia unit. The necessary material and personnel are as follows: (i) an anesthetist and an allergist throughout the DPT procedure and recovery; (ii) nurses trained in the management of airway and cardiovascular events; (iii) individualized monitoring (ECG, noninvasive blood pressure, pulse oximetry, and respiratory rate); (iv) resuscitation trolley and airway handling material; $(v)$ a ventilator or anesthesia machine, especially if the DPT is performed with muscle relaxants or in high-risk patients (Physical

Table 5. Doses Administered in the Drug Provocation Test

\begin{tabular}{|c|c|c|c|}
\hline Drug & Setting & Route & Maximum Dose \\
\hline \multicolumn{4}{|l|}{ Opioids } \\
\hline Morphine & $\mathrm{AU}$ & Oral & $5 \mathrm{mg} ; 10 \mathrm{mg}$ in $<65$ years \\
\hline Pethidine & & $\mathrm{SC}$ & $25 \mathrm{mg}$ \\
\hline Fentanyl & & $\mathrm{SC}$ & $50 \mu \mathrm{g}$ \\
\hline \multicolumn{4}{|l|}{ Benzodiazepines } \\
\hline Midazolam & $\mathrm{AU}$ & Oral & $3.5-5 \mathrm{mg}$ \\
\hline Diazepam & & Oral & $5-10 \mathrm{mg}$ \\
\hline \multicolumn{4}{|l|}{ Opioids } \\
\hline Morphine hydrochloride & PU & IV & $0.1 \mathrm{mg} / \mathrm{kg}(10 \mathrm{mg})$ \\
\hline Meperidine & & IV & $0.5 \mathrm{mg} / \mathrm{kg}(50 \mathrm{mg})$ \\
\hline Fentanyl & & IV & $1-2 \mu \mathrm{g} / \mathrm{kg}$ \\
\hline Alfentanil & & IV & $10-20 \mu \mathrm{g} / \mathrm{kg}$ \\
\hline Remifentanil & & IV & Continuous infusion $(0.05-0.1 \mu \mathrm{g} / \mathrm{kg} / \mathrm{min})$ \\
\hline Sufentanil & & IV & $0.1 \mu \mathrm{g} / \mathrm{kg}$ \\
\hline \multicolumn{4}{|l|}{ Hypnotics } \\
\hline Propofol & PU & IV & $1-2 \mathrm{mg} / \mathrm{kg}$ \\
\hline Etomidate & & IV & $0.2-0.3 \mathrm{mg} / \mathrm{kg}$ \\
\hline Ketamine & & IV & $0.5-2 \mathrm{mg} / \mathrm{kg}$ \\
\hline \multicolumn{4}{|l|}{ NMBAs } \\
\hline Cisatracurium & PU & IV & $0.5 \mathrm{mg} / \mathrm{kg}$ \\
\hline Atracurium & & IV & $0.1-0.15 \mathrm{mg} / \mathrm{kg}$ \\
\hline Rocuronium & & IV & $0.6 \mathrm{mg} / \mathrm{kg}$ \\
\hline Vecuronium & & IV & $0.1 \mathrm{mg} / \mathrm{kg}$ \\
\hline
\end{tabular}

Abbreviations: AU, allergology unit; IV, intravenous; NMBA, neuromuscular blocking agent; PU, postanesthetic unit; SC, subcutaneous. 
Status Classification System of the American Society of Anesthesiology [ASA] 3 and 4) [150].

Extra considerations may include the following: (i) 2 signed informed consents, one for the allergological study and the other for the anesthetic procedure, specifying the risks of each procedure and with a previous study in the allergology and anesthesiology units; (ii) possibility of nonspecific histamine release and hypotension with certain drugs (succinylcholine, rocuronium, atracurium, mivacurium, morphine, and meperidine), which can hamper diagnosis [143,145,151]; (iii) the complexity of the procedure requires DPT with different drugs consecutively on the same day, with 1-hour intervals between each drug. This is possible, as drugs are administered intravenously and most reactions appear in less than 30 minutes; (iv) monitoring of the patient during the recovery phase after finishing the DPT.

The drugs that usually need to be tested are opioids, because there is no alternative and hypnotics that are essential for anesthetic induction, particularly propofol, are the most widely used agents for anesthesia and sedation [78,80,152]. Testing is not recommended for muscle relaxants owing to potential effects on breathing, with the exception of those cases where they are suspected of causing a reaction and where they are absolutely necessary to perform surgery and no alternatives exist [144]. Testing is indicated in specific situations where the anesthetist needs to know tolerance to NMBAs, for example, in transplant procedures, high-risk patients, or when skin tests are not valuable. As NBMAs cannot be used alone, it is recommended to test them after other drugs, such as propofol, to control the airway by endotracheal intubation, which will enable better control in case of a reaction. It is recommended to test a muscle relaxant other than that inducing the reaction. This should yield negative skin test and BAT results, and, if possible, be from a different chemical group, especially in the case of cisatracurium and rocuronium $[9,146,151]$.

\section{Recommendations After the Allergological Study}

Once the allergological study is finished, a medical report must be produced with a detailed description of the drugs involved, the type of reaction, the allergology work-up results, diagnosis, and recommendations (grade of recommendation, D). This will be essential when deciding on the best anesthetic procedures for the patient in the future. The various possibilities are as follows:

- Patient with a clinical history that not suggestive and negative allergology findings.

If the patient has not presented a hypersensitivity drug reaction, the recommendation is to use any anesthetic procedure with the same risk as for the general population (grade of recommendation, D).

- Patient with a suggestive clinical history and negative allergology results.

In this scenario, the various possibilities are as follows:

- If the allergological study has only been based on the performance of skin tests accompanied or not by in vitro tests and a drug provocation test cannot be performed, then it is not possible to rule out an allergic reaction [109]. If the drugs involved in the reaction are known, the best approach is to avoid them as well as any others that may cause cross-reactivity (grade of recommendation, D). If the drugs involved are not known, the best approach is to use locoregional anesthesia (if possible) or general anesthesia, but without using NMBAs or drugs with a high capacity to induce nonspecific histamine release (grade of recommendation, D) [6]. Moreover, it is important to re-evaluate the patient by testing emerging agents such as chlorhexidine, methylcellulose, polyethylene glycol/macrogol, mannitol, dyes, and any other drugs not initially considered due to improbability. It is also important to assess any methodological problems in the testing procedures (failure in concentration or skin test reading) (grade of recommendation, D).

- If the allergological study was based on provocation testing, drugs with confirmed tolerance will be recommended (grade of recommendation, D).

- In cases where nonspecific histamine release is suspected, the recommendation is to avoid drugs with potent histamine-releasing capacity the next time anesthesia is administered. Pretreatment with antihistamines is also recommended $[11,153]$, and all drugs should be administered slowly and one by one $[10,145]$ (grade of recommendation, D).

- Patient with a suggestive clinical history and positive allergology results.

The recommendation is to avoid the agent identified as allergic and those with cross-reactivity. In these cases, pretreatment is not useful for preventing a new reaction [154]. The recommendations will depend on the culprit drug, as follows:

- NMBAs. The recommendation is to use a muscle relaxant that yields negative results in intradermal skin tests and the BAT $[12,140]$. Although there is considerable cross-reactivity between muscle relaxants (65\% if the reaction was induced by rocuronium and $29 \%$ for succinylcholine) [155], sensitization to all of them is low (grade of recommendation, C) [146]. If this is the case and all NMBAs yield positive results in skin tests and/or BAT, one might consider a locoregional anesthesia or tracheal intubation after induction of anesthesia using inhalant agents or combinations of opioids and hypnotics (midazolam, propofol, fentanyl) plus local anesthetics such as lidocaine [154-156] (grade of recommendation, D).

- Hypnotics. Since hypnotics do not present crossreactivity, it should be possible to replace one hypnotic with another. Currently, most reactions are due to propofol. Ketamine and etomidate provide effective sedation with limited effects on hemodynamic function. The better alternative in patients with cardiovascular disease is etomidate. Ketamine induces dissociative anesthesia with minimum respiratory depression and no cardiodepressant effects and is especially useful in hemodynamically unstable patients or critically ill patients. Thiopental is rarely used nowadays. In cases of endoscopy, a combination of midazolam and fentanyl has been recommended [157]. 
- Opioids. The incidence of anaphylaxis is quite low, and most cases are due to nonspecific histamine release. In such cases, it is important to avoid morphine, meperidine, and codeine, all of which have a high capacity for stimulating mast cells in the skin. Recommended alternatives include phenylpiperidine drugs (fentanyl, alfentanil, remifentanil, sufentanil), which have a low histamine release capacity. In IgEmediated reactions induced by morphine, it seems useful to use remifentanil or fentanyl; morphine can be used in cases of reaction to fentanyl [83-86].

- Colloids/crystalloids. Gelatins and dextrans are the substances most frequently involved [158]. Crossreactivity between them has not been reported.

- Latex. Every hospital should have protocols for operations involving patients with latex allergy. If there is no specific operating room, then the surgery should be performed early in the day and without materials containing latex in order to avoid the presence of latex particles in the environment [113]. Similar precautions should be taken when the patient is moved to the postsurgery room or any other part of the hospital [113].

- Local anesthetic. Reactions are quite infrequent and are generally not due to hypersensitivity. If confirmed, an alternative with confirmed tolerance can be used.

- Dyes. Reactions have been mainly reported for patent blue $\mathrm{V}$ and isosulfan blue, which cross-react. Methylene blue can be used as an alternative if the allergological study is negative [159].

- Antiseptics and sterilizers. In cases for which hypersensitivity to chlorhexidine or povidone-iodine is confirmed, they should be avoided, and other drugs without cross-reactivity should be used. When this is not possible, as with ethylene oxide, the area should be washed several times in physiological saline before use. The same procedure should be followed with ortho-phthalaldehyde solution, although this has generally been replaced by peracetic acid owing to its higher sensitizing capacity.

\section{Acknowledgments}

We thank Paloma Campo and James Perkins for their help in reviewing the English version of the manuscript and Ignacio Davila for external review. JJ Laguna Martínez, G Gastamiza, C Mayorga, I Doña, and MJ Torres are members of the RETIC ARADYAL RD16/0006/000, which was supported by Institute of Health "Carlos III" of the Ministry of Economy and Competitiveness (grants cofunded by the European Regional Development Fund). I Doña holds a Juan Rodes research contract (JR15/00036) from the Institute of Health "Carlos III" of the Ministry of Economy and Competitiveness (grants cofunded by the European Regional Development Fund).

\section{Funding}

The authors declare that no funding was received for the present study.

\section{Conflicts of Interest}

The authors declare that they have no conflicts of interest.

\section{References}

1. Laxenaire M-C, Mertes PM.Anaphylaxis during anaesthesia. Results of a two-year survey in France. Br J Anaesth. 2001;87:549-58.

2. Moss J. Allergic to anesthetics. Anesthesiology. 2003;99:521-3.

3. Volcheck GW, Mertes PM. Local and General Anesthetics Immediate Hypersensitivity Reactions. Immunol Allergy Clin North Am. 2014;34:525-46.

4. Malinovsky J-M, Decagny S, Wessel F, Guilloux L, Mertes PM. Systematic follow-up increases incidence of anaphylaxis during adverse reactions in anesthetized patients. Acta Anaesthesiol Scand. 2008:52:175-81.

5. Lobera T, Audicana MT, Pozo MD, Blasco A, Fernández E, Canada $P$, et al.Study of hypersensitivity reactions and anaphylaxis during anesthesia in Spain. J Investig Allergol Clin Immunol. 2008;18:350-6.

6. Berroa F, Lafuente A, Javaloyes G, Cabrera-Freitag P, de la Borbolla JM, Moncada R, et al. The Incidence of Perioperative Hypersensitivity Reactions: A Single-Center, Prospective, Cohort Study. Anesth Analg. 2015;121:117-23.

7. Mertes PM, Laxenaire M-C, Alla F, Peranesthésiques GdaEdRA. Anaphylactic and anaphylactoid reactions occurring during anesthesia in France in 1999-2000. Anesthesiology. 2003;99:536-45.

8. Whitaker DK, Bratteb G, Smith AF, Staender SE. The Helsinki Declaration on Patient Safety in Anaesthesiology: putting words into practice. Best Pract Res Clin Anaesthesiol. 2011;25:277-90.

9. Ewan PW, Dugu e P, Mirakian R, Dixon TA, Harper JN, Nasser SM. BSACl guidelines for the investigation of suspected anaphylaxis during general anaesthesia. Clin Exp Allergy. 2010;40:15-31.

10. Kroigaard M, Garvey LH, Gillberg L, Johansson SG, Mosbech H,

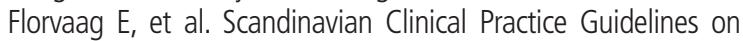
the diagnosis, management and follow-up of anaphylaxis during anaesthesia*. Acta Anaesthesiol Scand. 2007;51:655-70.

11. Mertes PM, Malinovsky JM, Jouffroy L, Aberer W, Terreehorst I, Brockow K, et al. Reducing the risk of anaphylaxis during anesthesia: 2011 updated guidelines for clinical practice. J Investig Allergol Clin Immunol. 2011;21:442-53.

12. Ebo DG, Fisher MM, Hagendorens MM, Bridts $C H$, Stevens WJ. Anaphylaxis during anaesthesia: diagnostic approach. Allergy. 2007;62:471-87.

13. Demoly P, Kropf R, Pichler WJ, Bircher A. Drug hypersensitivity: questionnaire. Allergy. 1999;54:999-1003.

14. Garvey LH. Practical aspects of perioperative anaphylaxis. Trends Anaesth Crit Care. 2013;3:320-6.

15. Schwartz LB. Diagnostic value of tryptase in anaphylaxis and mastocytosis. Immunol Allergy Clin North Am. 2006;26:451-63.

16. Mertes PM. Anaphylactic reactions during anaesthesia--let us treat the problem rather than debating its existence. Acta Anaesthesiol Scand. 2005;49:431-3.

17. Levy JH, Adkinson NF. Anaphylaxis during cardiac surgery: implications for clinicians. Anesth Analg. 2008;106:392-403.

18. Harbour R, Miller J.A new system for grading recommendations in evidence based guidelines. BMJ. 2001;323:334-6. 
19. Johansson SG, Bieber $T$, Dahl R, Friedmann PS, Lanier BQ, Lockey RF, et al. Revised nomenclature for allergy for global use: Report of the Nomenclature Review Committee of the World Allergy Organization, October 2003. J Allergy Clin Immunol. 2004;113:832-6.

20. Mertes PM, Alla F, Trechot P, Auroy Y, Jougla E. Anaphylaxis during anesthesia in France: an 8-year national survey. J Allergy Clin Immunol. 2011;128:366-73.

21. Florvaag $E$, Johansson SG, Oman H, Venemalm L, Degerbeck $F$, Dybendal T, et al. Prevalence of IgE antibodies to morphine. Relation to the high and low incidences of NMBA anaphylaxis in Norway and Sweden, respectively. Acta Anaesthesiol Scand. 2005;49:437-44.

22. Dong S, Acouetey DS, Gueant-Rodriguez R-M, ZmirouNavier D, Remen T, Blanca M, et al. Prevalence of IgE against neuromuscular blocking agents in hairdressers and bakers. Clin Exp Allergy. 2013;43:1256-62.

23. Gueant JL, Masson C, Laxenaire MC. Biological tests for diagnosing the IgE-mediated allergy to anesthetic drugs. Monogr Allergy. 1992;30:94-107.

24. Limsuwan T, Demoly P.Acute symptoms of drug hypersensitivity (urticaria, angioedema, anaphylaxis, anaphylactic shock). Med Clin North Am. 2010;94:691-710.

25. Hedin H, Richter W. Pathomechanisms of Dextran-Induced Anaphylactoid/Anaphylactic Reactions in Man. Int Arch Allergy Immunol. 1982;68:122-6.

26. Doenicke AW, Czeslick E, Moss J, Hoernecke R. Onset Time. Endotracheal Intubating Conditions, and Plasma Histamine After Cisatracurium and Vecuronium Administration. Anesth Analg. 1998:87:434-8.

27. Koppert W, Blunk Ja, Petersen LJ, Skov P, Rentsch K, Schmelz M. Different Patterns of Mast Cell Activation by Muscle Relaxants in Human Skin. Anesthesiology. 2001;95:659-67.

28. Nel L, Eren E. Peri-operative anaphylaxis. Br J Clin Pharmacol. 2011;71:647-58.

29. Khan Da, Solensky R. Drug allergy. J Allergy Clin Immunol. 2010;125: S126-37.

30. Fisher MM, Baldo BA. The incidence and clinical features of anaphylactic reactions during anesthesia in Australia. Ann Fr Anesth Reanim. 1993;12:97-104.

31. Mertes PM, Tajima K, Regnier-Kimmoun MA, Lambert M, lohom G, Gueant-Rodriguez RM, et al. Perioperative anaphylaxis. Med Clin North Am. 2010;94:761-89.

32. Chacko T, Ledford D. Peri-anesthetic anaphylaxis. Immunol Allergy Clin North Am. 2007;27:213-30.

33. Harboe $T$, Guttormsen AB, Irgens A, Dybendal T, Florvaag $E$. Anaphylaxis during anesthesia in Norway: a 6-year singlecenter follow-up study. Anesthesiology. 2005;102:897903.

34. Hunting AS, Nopp A, Johansson SG, Andersen F, Wilhelmsen V, Guttormsen AB. Anaphylaxis to Patent Blue V. I. Clinical aspects. Allergy. 2010:65:117-23.

35. Mertes PM, Malinovsky J-M, Mouton-Faivre C, Bonnet-Boyer MC, Benhaijoub A, Lavaud F, et al. Anaphylaxis to dyes during the perioperative period: reports of 14 clinical cases. J Allergy Clin Immunol. 2008;122:348-52.

36. Garvey LH, Krigaard M, Poulsen LK, Skov PS, Mosbech $H_{\text {, }}$ Venemalm L, et al. IgE-mediated allergy to chlorhexidine. J Allergy Clin Immunol. 2007:120:409-15.
37. Johansson SG, Florvaag $E$, Oman H, Poulsen LK, Mertes PM, Harper NJ, et al. National pholcodine consumption and prevalence of IgE-sensitization: a multicentre study. Allergy. 2010;65:498-502

38. Mertes PM, Laxenaire M-C. Allergy and anaphylaxis in anaesthesia. Minerva Anestesiol. 2004;70:285-91.

39. Hepner DL, Castells MC. Anaphylaxis During the Perioperative Period. Anesth Analg. 2003:97:1381-95.

40. Dewachter P, Mouton-Faivre C, Emala CW. Anaphylaxis and anesthesia: controversies and new insights. Anesthesiology. 2009;111:1141-50

41. Harper NJ, Dixon T, Dugue P, Edgar DM, Fay A, Gooi HC, et al. Suspected anaphylactic reactions associated with anaesthesia. Anaesthesia. 2009;64:199-211.

42. Sampson HA, Muñoz-Furlong $A$, Campbell RL, Adkinson NF, Bock SA, Branum A, et al. Second symposium on the definition and management of anaphylaxis: summary report--Second National Institute of Allergy and Infectious Disease/Food Allergy and Anaphylaxis Network symposium. J Allergy Clin Immunol. 2006;117:391-7.

43. Simons FER. Anaphylaxis. J Allergy Clin Immunol. 2010;125:S161-81.

44. Kanji S, Chant C. Allergic and hypersensitivity reactions in the intensive care unit. Crit Care Med. 2010;38:S162-8.

45. Franco Hernández JA, García Hernández A, Lahoz Rodríguez D. [Kounis syndrome secondary to an allergic reaction to metamizole]. Rev Esp Anestesiol Reanim. 2012;59:217-9.

46. Rico Cepeda P, Palencia Herrejón E, Rodríguez Aguirregabiria MM. [Kounis syndrome]. Med Intensiva. 2013;36:358-64

47. Michavila Gomez AV, Belver Gonzalez MT, Alvarez NC, Giner Munoz MT, Hernando Sastre V, Porto Arceo JA, et al. Drug allergy Work Group of the Spanish Society of Paediatric Allergy I. Perioperative anaphylactic reactions: Review and procedure protocol in paediatrics. Allergol Immunopathol (Madr). 2015:43:203-14.

48. Fisher MM, Ramakrishnan N, Doig G, Rose M, Baldo B The investigation of bronchospasm during induction of anaesthesia. Acta Anaesthesiol Scand. 2009:53:1006-11.

49. De Souza RL, Short T, Warman GR, Maclennan N, Young Y. Anaphylaxis with associated fibrinolysis, reversed with tranexamic acid and demonstrated by thrombelastography. Anaesth Intensive Care. 2004;32:580-7.

50. Mirone C, Preziosi D, Mascheri A, Micarelli G, Farioli L, Balossi $L G$, et al. Identification of risk factors of severe hypersensitivity reactions in general anaesthesia. Clin Mol Allergy. 2015;13:11.

51. Garvey LH, Belhage B, Krigaard M, Husum B, Malling H-Jr, Mosbech $H$. Treatment with epinephrine (adrenaline) in suspected anaphylaxis during anesthesia in Denmark. Anesthesiology. 2011:115:111-6.

52. Escolano F, Valero A, Huguet J, Baxarias P, de Molina M, Castro $A$, et al. [Prospective epidemiologic study of perioperative anaphylactoid reactions occurring in Catalonia (1996-7)]. Rev Esp Anestesiol Reanim. 2002;49:286-93.

53. Kemp AM, Kemp SF. Pharmacotherapy in refractory anaphylaxis: when intramuscular epinephrine fails. Curr Opin Allergy Clin Immunol. 2014;14:371-8.

54. Campbell RL, Li JT, Nicklas RA, Sadosty AT, Members of the Joint Task Force. Practice Parameter Workgroup, Emergency 
department diagnosis and treatment of anaphylaxis: a practice parameter. Ann Allergy Asthma Immunol. 2014;113:599-608.

55. Lo JC, Darracq MA, Clark RF. A review of methylene blue treatment for cardiovascular collapse. J Emerg Med. 2014;46:670-9.

56. Zheng F, Barthel G, Collange O, Montémont C, Thornton SN, Longrois D, et al. Methylene blue and epinephrine: a synergetic association for anaphylactic shock treatment. Crit Care Med. 2013:41:195-204

57. Sheikh A, Ten Broek V, Brown SG, Simons FER. H1antihistamines for the treatment of anaphylaxis: Cochrane systematic review. Allergy. 2007;62:830-7.

58. Choo KJL, Simons FER, Sheikh A. Glucocorticoids for the treatment of anaphylaxis. Cochrane systematic review. Allergy. 2010;65:1205-11.

59. Mcdonnell NJ, Pavy TJG, Green LK, Platt PR. Sugammadex in the management of rocuronium-induced anaphylaxis. $\mathrm{Br} J$ Anaesth. 2011;106:199-201.

60. Barthel F, Stojeba N, Lyons G, Biermann C, Diemunsch P. Sugammadex in rocuronium anaphylaxis: dose matters. $\mathrm{Br} J$ Anaesth. 2012:109:646-7.

61. Platt PR, Clarke RC, Johnson GH, Sadleir PHM. Efficacy of sugammadex in rocuronium-induced or antibioticinduced anaphylaxis. A case-control study. Anaesthesia. 2015;70:1264-7.

62. Alter HJ, Koepsell TD, Hilty WM. Intravenous magnesium as an adjuvant in acute bronchospasm: a meta-analysis. Ann Emerg Med. 2000;36:191-7.

63. Berroa F, Lafuente $A$, Javaloyes G, Ferrer $M$, Moncada $R_{\text {, }}$ Goikoetxea MJ, et al. The usefulness of plasma histamine and different tryptase cut-off points in the diagnosis of peranaesthetic hypersensitivity reactions. Clin Exp Allergy. 2014;44:270-7.

64. Soar J, Pumphrey R, Cant A, Clarke S, Corbett A, Dawson $P$, et al. Working Group of the Resuscitation C. Emergency treatment of anaphylactic reactions-guidelines for healthcare providers. Resuscitation. 2008;77:157-69.

65. Adriaensens I, Vercauteren $M$, Soetens $F$, Janssen $L$, Leysen J, Ebo D. Allergic reactions during labour analgesia and caesarean section anaesthesia. Int J Obstet Anesth. 2013:22:231-42.

66. Antunes J, Kochuyt A, Ceuppens JL. Perioperative allergic reactions: Experience in a Flemish referral centre. Allergol Immunopathol (Madr). 2014;42:348-54.

67. Sivagnanam S, Deleu D. Red man syndrome. Crit Care 2003;7:119-20

68. Blanca-López N, Andreu I, Torres Jaén MJ. Hypersensitivity reactions to quinolones. Curr Opin Allergy Clin Immunol. 2011:11:285-91.

69. Bratzler DW, Houck PM. Antimicrobial prophylaxis for surgery: an advisory statement from the National Surgical Infection Prevention Project. Am J Surg. 2005; 189:395-404.

70. Mertes PM, Demoly P, Malinovsky JM. Hypersensitivity reactions in the anesthesia setting/allergic reactions to anesthetics. Curr Opin Allergy Clin Immunol. 2012;12:361-8.

71. Low AE, McEwan JC, Karanam S, North J, Kong K-L. Anaesthesia-associated hypersensitivity reactions: seven years' data from a British bi-specialty clinic. Anaesthesia. 2016;71:76-84.
72. Baldo BA, Fisher MM, Pham NH. On the origin and specificity of antibodies to neuromuscular blocking (muscle relaxant) drugs: an immunochemical perspective. Clin Exp Allergy. 2009:39:325-44.

73. Menéndez-Ozcoidi L, Ortiz-Gómez JR, Olaguibel-Ribero JM, Salvador-Bravo MJ. Allergy to low dose sugammadex. Anaesthesia. 2011;66:217-9.

74. Soria A, Motamed C, Gaouar H, Chemam S, Amsler $E$, Francès $C$. Severe reaction following sugammadex injection: hypersensitivity? J Investig Allergol Clin Immunol. 2012;22:382.

75. Jeyadoss J, Kuruppu P, Nanjappa N, Van Wijk R. Sugammadex hypersensitivity-a case of anaphylaxis. Anaesth Intensive Care. 2014;42:89-92.

76. Godai K, Hasegawa-Moriyama M, Kuniyoshi T, Kakoi T, Ikoma K, Isowaki $\mathrm{S}$, et al. Three cases of suspected sugammadex-induced hypersensitivity reactions. Br J Anaesth. 2012;109:216-8.

77. Harle DG, Baldo BA, Fisher MM. The molecular basis of $\lg \mathrm{E}$ antibody binding to thiopentone. Binding of $\lg E$ from thiopentone-allergic and non-allergic subjects. Mol Immunol. 1990;27:853-8.

78. Asserhøj LL, Mosbech H, Kroigaard M, Garvey LH. No evidence for contraindications to the use of propofol in adults allergic to egg, soy or peanut. Br J Anaesth. 2016;116:77-82.

79. Dewachter P, Mouton-Faivre C, Castells MC, Hepner DL. Anesthesia in the patient with multiple drug allergies: are all allergies the same? Curr Opin Anaesthesiol. 2011;24:320-5.

80. Molina-Infante J, Arias A, Vara-Brenes D, Prados-Manzano R, Gonzalez-Cervera J, Alvarado-Arenas M, et al. Propofol administration is safe in adult eosinophilic esophagitis patients sensitized to egg, soy, or peanut. Allergy. 2014;69: 388-94.

81. Karila C, Brunet Langot D, Labbez F, Jacqmarcq O, Ponvert C, Paupe $J$, et al. Anaphylaxis during anesthesia: results of a 12-year survey at a French pediatric center. Allergy. 2005;60:828-34.

82. Harle DG, Baldo BA, Coroneos NJ, Fisher MM. Anaphylaxis following administration of papaveretum. Case report: Implication of $\operatorname{lgE}$ antibodies that react with morphine and codeine, and identification of an allergenic determinant. Anesthesiology. 1989;71:489-94.

83. Anibarro B, Vila C, Seoane FJ. Urticaria induced by meperidine allergy. Allergy. 2000;55:305-6.

84. Cummings KC, Arnaut K. Case report: Fentanyl-associated intraoperative anaphylaxis with pulmonary edema. Can J Anaesth. 2007:54:301-6.

85. Zucker-Pinchoff B, Ramanathan S. Anaphylactic reaction to epidural fentanyl. Anesthesiology.1989;71:599-601.

86. Dewachter P, Lefebvre D, Kalaboka S, Bloch-Morot E. An anaphylactic reaction to transdermal delivered fentanyl. Acta Anaesthesiol Scand. 2009;53:1092-3.

87. Brockow K, Romano a, Blanca M, Ring J, Pichler W, Demoly P. General considerations for skin test procedures in the diagnosis of drug hypersensitivity. Allergy. 2002;57:45-51.

88. Gall H, Kaufmann R, Kalveram CM. Adverse reactions to local anesthetics: Analysis of 197 cases. J Allergy Clin Immunol. 1996:97:933-7.

89. Calderon AL, Diot N, Benatir F, Christin F, Hautin E, Truc C,

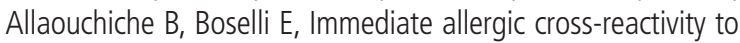
levobupivacaine and ropivacaine. Anaesthesia. 2013;68:203-5. 
90. Lucas-Polomeni M-M, Delaval Y, Menestret $P$, Delaval $P$, Ecoffey C. [A case of anaphylactic shock with tranexamique acid (Exacyl)]. Ann Fr Anesth Reanim. 2004;23:607-9.

91. Maycock EJ, Russell WC. Anaphylactoid reaction to syntocinon. Anaesth Intensive Care. 1993;21:211-2.

92. Lin MC, Hsieh TK, Liu CA, Chu CC, Chen JY, Wang JJ, et al. Anaphylactoid shock induced by oxytocin administration--a case report. Acta Anaesthesiol Taiwan. 2007;45:233-6.

93. Coelho D, Fernandes T, Branga P, Malheiro D, Rodrigues J. Intraoperative anaphylaxis after intravenous atropine. Eur J Anaesthesiol. 2007;24:289-90.

94. Russell WJ, Fenwick DG. Anaphylaxis to Haemaccel and cross reactivity to Gelofusin. Anaesth Intensive Care. 2002;30:481-3.

95. Uyttebroek A, Sabato V, Bridts CH, De Clerck LS, Ebo DG. Anaphylaxis to succinylated gelatin in a patient with a meat allergy: galactose-alpha(1, 3)-galactose (alpha-gal) as antigenic determinant. J Clin Anesth. 2014;26:574-6.

96. Kim HJ, Kim SY, Oh MJ, Kim JM. Anaphylaxis induced by hydroxyethyl starch during general anesthesia -A case reportKorean Journal of Anesthesiology. 2012;63:260.

97. Ebo DG, Schuerwegh A, Stevens WJ. Anaphylaxis to starch. Allergy. 2000;55:1098-9.

98. Nybo M, Madsen JS. Serious anaphylactic reactions due to protamine sulfate: a systematic literature review. Basic Clin Pharmacol Toxicol. 2008;103:192-6.

99. Dietrich W, Spath P, Zuhlsdorf M, Dalichau H, Kirchhoff PG, Kuppe $\mathrm{H}$, et al. Anaphylactic reactions to aprotinin reexposure in cardiac surgery: relation to antiaprotinin immunoglobulin $\mathrm{G}$ and E antibodies. Anesthesiology. 2001;95:64-71;discussion 5A-6A.

100. Beierlein $W$, Scheule AM, Dietrich $W$, Ziemer G. Forty years of clinical aprotinin use: a review of 124 hypersensitivity reactions. Ann Thorac Surg. 2005;79:741-8.

101. Lee HK, Choi EJ, Lee PB, Nahm FS. Anaphylactic Shock Caused by the Epidurally-Administered Hyalurinidase. Korean J Pain. 2011;24:221-5.

102. Eberhart $A H$, Weiler CR, Erie JC. Angioedema related to the use of hyaluronidase in cataract surgery. Am J Ophthalmol. 2004;138:142-3.

103. Opstrup MS, Malling HJ, Kroigaard M, Mosbech H, Skov PS, Poulsen LK, et al. Standardized testing with chlorhexidine in perioperative allergy--a large single-centre evaluation. Allergy. 2014;69:1390-6.

104. Garvey LH, Roed-Petersen J, Husum B. Anaphylactic reactions in anaesthetised patients - four cases of chlorhexidine allergy. Acta Anaesthesiol Scand. 2001;45:1290-4.

105. Garvey LH, Roed-Petersen J, Husum B. Is there a risk of sensitization and allergy to chlorhexidine in health care workers? Acta Anaesthesiol Scand. 2003;47:720-4.

106. Breu FX, Guggenbichler S, Wollmann JC. 2nd European Consensus Meeting on Foam Sclerotherapy 2006, Tegernsee, Germany. Vasa. 2008;37 suppl 71:1-29.

107. Ramin S, Azar FP, Malihe H. Methylene blue as the safest blue dye for sentinel node mapping: emphasis on anaphylaxis reaction. Acta Oncol. 2011;50:729-31.

108. Komenaka IK, Bauer VP, Schnabel FR, Horowitz E, Joseph $K A$, Ditkoff $B-A$, et al. Allergic reactions to isosulfan blue in sentinel lymph node mapping. Breast J. 2005;11:70-2.

109. Keller B, Yawalkar N, Pichler C, Braathen LR, Hunger RE, Hypersensitivity reaction against patent blue during sentinel lymph node removal in three melanoma patients. Am J Surg. 2007;193:122-4.

110. Blaabjerg MS, Andersen KE, Bindslev-Jensen C, Mortz CG. Decrease in the rate of sensitization and clinical allergy to natural rubber latex. Contact Dermatitis. 2015;73:21-8.

111. Krishna MT, York M, Chin T, Gnanakumaran G, Heslegrave J, Derbridge C, et al. Multi-centre retrospective analysis of anaphylaxis during general anaesthesia in the United Kingdom: aetiology and diagnostic performance of acute serum tryptase. Clin Exp Immunol. 2014;178:399-404.

112. Katz J, Holzman R, Brown R, Katz: Natural rubber latex allergy: consideration for anesthesiologists" Park Ridge, IL. American Society of Anesthesiologists 2005:1-30.

113. Cabañes $N$, Igea JM, de la Hoz B, Agustin P, Blanco C, Dominguez J, et al. Latex allergy: Position Paper. J Investig Allergol Clin Immunol. 2012;22:313-30

114. Kvedariene $V$, Kamey S, Ryckwaert $Y$, Rongier $M$, Bousquet J, Demoly $\mathrm{P}$, et al. Diagnosis of neuromuscular blocking agent hypersensitivity reactions using cytofluorimetric analysis of basophils. Allergy. 2006;61:311-5.

115. Fernandez TD, Torres MJ, Blanca-Lopez N, Rodriguez-Bada $J$, Gomez E, Canto G, et al. Negativization rates of $\operatorname{lgE}$ radioimmunoassay and basophil activation test in immediate reactions to penicillins. Allergy. 2009;64:242-8.

116. Baldo BA, Pham NH. Histamine-releasing and allergenic properties of opioid analgesic drugs: resolving the two. Anaesth Intensive Care. 2012;40:216-35.

117. Demoly P, Adkinson NF, Brockow K, Castells M, Chiriac AM, Greenberger PA, et al. International Consensus on drug allergy. Allergy. 2014;69:420-37.

118. Mertes PM, Moneret-Vautrin DA, Leynadier F, Laxenaire $M-C$. Skin reactions to intradermal neuromuscular blocking agent injections: a randomized multicenter trial in healthy volunteers. Anesthesiology. 2007;107:245-52.

119. Brockow K, Garvey LH, Aberer W, Atanaskovic Markovic $M$, Barbaud A, Bilo $M B$, et al. Skin test concentrations for systemically administered drugs - an ENDA/EAACI Drug Allergy Interest Group position paper. Allergy. 2013;68:702-12.

120. Moneret-Vautrin DA. [Skin tests for diagnosis of curare allergy]. Ann Fr Anesth Reanim. 2002;21 Suppl 1:97s-107s.

121. Moneret-Vautrin DA, Gueant JL, Kamel L, Laxenaire MC, el Kholty $S$, Nicolas JP. Anaphylaxis to muscle relaxants: cross-sensitivity studied by radioimmunoassays compared to intradermal tests in 34 cases. J Allergy Clin Immunol. 1988;82:745-52.

122. Turjanmaa K, Palosuo T, Alenius H, Leynadier F, Autegarden $J E$, André $C$, et al. Latex allergy diagnosis: in vivo and in vitro standardization of a natural rubber latex extract. Allergy. 1997; 52:41-50

123. Torres J, Romano A, Mayorga C, Carmen M, Guzman AE, Reche $M$, et al. Diagnostic evaluation of a large group of patients with immediate allergy to penicillins: the role of skin testing. Allergy. 2001;56:850-6.

124. Ortega N, Doña I, Moreno E, Audicana MT, Barasona MJ, Berges-Gimeno MP, et al. Practical guidelines for diagnosing hypersensitivity reactions to nonsteroidal anti-inflammatory drugs. J Investig Allergol Clin Immunol. 2014;24:308-23.

125. McNeill O, Kerridge RK, Boyle MJ. Review of procedures for investigation of anaesthesia-associated anaphylaxis in Newcastle, Australia. Anaesth Intensive Care. 2008;36:201-7. 
126. Takazawa T, Tomita Y, Yoshida N, Tomioka A, Horiuchi T, Nagata $C$, et al. Three suspected cases of sugammadexinduced anaphylactic shock. BMC Anesthesiol. 2014;14:92.

127. Dewachter P, Mouton-Faivre C, Trechot P, Lleu J-C, Mertes PM. Severe anaphylactic shock with methylene blue instillation. Anesth Analg. 2005;101:149-50.

128. Tamayo E, Perez M, Gomez Jl, Alvarez FJ. Allergy of anaesthetizing agents in Spain. Br J Anaesth. 1999;83:336-7.

129. Caimmi S, Caimmi D, Cardinale F, Indinnimeo L, Crisafulli G, Peroni DG, et al. Perioperative allergy: uncommon agents. Int J Immunopathol Pharmacol. 2011;24:S61-8.

130. Parkes AW, Harper N, Herwadkar A, Pumphrey R. Anaphylaxis to the chlorhexidine component of Instillagel: a case series. $\mathrm{Br}$ J Anaesth. 2009;102:65-8.

131. Soetens $F$, Rose $M$, Fisher M. Timing of skin testing after a suspected anaphylactic reaction during anaesthesia. Acta Anaesthesiol Scand. 2012;56:1042-6.

132. Enrique E, García Ortega P, Gaig P, Richart C, Sotorra 0. Usefulness of UniCAP-Tryptase fluoroimmunoassay in the diagnosis of anaphylaxis. Allergy. 1999;54:602-6.

133. Sprung J, Weingarten TN, Schwartz LB. Presence or absence of elevated acute total serum tryptase by itself is not a definitive marker for an allergic reaction. Anesthesiology. 2015;122:713-4.

134. Laroche $D$, Chollet-Martin S, Leturgie $P$, Malzac L, Vergnaud $M-C$, Neukirch $C$, et al. Evaluation of a new routine diagnostic test for immunoglobulin e sensitization to neuromuscular blocking agents. Anesthesiology. 2011;114:91-7.

135. Cottineau C, Drouet M, Costerousse F, Dussaussoy C, Sabbah A. [Importance of plasma (histamine and tryptase) and urinary (methylhistamine) in peri-anesthetic anaphylactic and/or anaphylactoid reactions]. Allerg Immunol (Paris). 1996;28:270, 273-6.

136. Laroche D, Gomis P, Gallimidi E, Malinovsky J-M, Mertes PM. Diagnostic Value of Histamine and Tryptase Concentrations in Severe Anaphylaxis with Shock or Cardiac Arrest during Anesthesia. Anesthesiology. 2014;121:272-9.

137. Dybendal T, Guttormsen AB, Elsayed S, Askeland B, Harboe T, Florvaag E. Screening for mast cell tryptase and serum IgE antibodies in 18 patients with anaphylactic shock during general anaesthesia. Acta Anaesthesiol Scand. 2003;47:1211-8.

138. Mayorga C, Celik G, Rouzaire P, Whitaker P, Bonadonna P, Cernadas JR, et al. In vitro tests for Drug Hypersensitivity Reactions: An ENDA/EAACI Drug Allergy Interest Group Position Paper. Allergy. 2016;71(8):1103-34.

139. Uyttebroek AP, Sabato V, Leysen J, Bridts CH, De Clerck LS, Ebo DG. Flowcytometric diagnosis of atracurium-induced anaphylaxis. Allergy. 2014;69:1324-32.

140. Leysen J, Uyttebroek A, Sabato V, Bridts CH, De Clerck LS, Ebo DG. Predictive value of allergy tests for neuromuscular blocking agents: tackling an unmet need. Clin Exp Allergy. 2014:44:1069-75.

141. Mata E, Gueant JL, Moneret-Vautrin DA, Bermejo N, Gerard $P$, Nicolas JP, et al. Clinical evaluation of in vitro leukocyte histamine release in allergy to muscle relaxant drugs. Allergy. 1992; 47:471-6.

142. Garcia-Aviles C, Sanz ML, Gamboa PM, Urrutia I, Antepara I, Jauregui I, et al. Antigen specific quantification of sulfidoleukotrienes in patients allergic to Betalactam antibiotics. J Investig Allergol Clin Immunol. 2005;15:37-45.

143. Aberer W, Bircher A, Romano A, Blanca M, Campi P, Fernandez $J$, et al. Drug provocation testing in the diagnosis of drug hypersensitivity reactions: general considerations. Allergy. 2003;58:854-63.

144. Brockow K. Dilemmas of allergy diagnosis in perioperative anaphylaxis. Allergy. 2014;69:1265-6.

145. Sánchez Palacios A, Ortiz Ponce M, Rodríguez Pérez A. [Allergic reactions and pseudoallergies in surgical interventions with general anesthesia]. Allergol Immunopathol (Madr). 2000;28:24-36.

146. Mertes PM, Laxenaire M-C, Lienhart A, Aberer W, Ring J, Pichler WJ, et al. Reducing the risk of anaphylaxis during anaesthesia: guidelines for clinical practice. J Investig Allergol Clin Immunol. 2005;15:91-101.

147. Tornero C. In: Fundamentos y Manejo Clínico Anestesia. Madrid, España: Editorial Médica Panamericana, 2015.

148. Miller RD. In: Miller's Anaesthesia. Philadelphia PA: Churchill Livingstone: Elsevier Health Sciences, 2010.

149. http://www.aemps.gob.es/

150. http://www.asahq.org, ASA Physical Status Classification System of the American Society of Anaesthesiology

151. Selcuk M, Celebioglu B, Celiker V, Basgul E, Aypar U. Infusion and bolus administration of cisatracurium--effects on histamine release. Middle East J Anaesthesiol. 2005;18:407-19.

152. Allchurch LG, Crilly H. Fixed drug eruption to propofol. Anaesth Intensive Care. 2014;42:777-81.

153. Xiang Z, Yan-Liang Q, Xiao-Yang S, Yan-Hui Z, Min C, GuoShen $G$, et al. Effects of promethazine or dexamethasone pretreatment on mivacurium-induced histamine release in children. Paediatr Anaesth. 2014;24:322-6.

154. Malinovsky JM, Lavaud F, Mertes PM. Les particularités de l'anesthésie générale chez le patient asthmatique. Rev $\mathrm{Fr}$ Allergol. 2011;51:148-56.

155. Brereton A, Russell WJ. Anaphylaxis to muscle relaxants: an audit of ten years of allergy testing at the Royal Adelaide Hospital. Anaesth Intensive Care. 2012;40:861-6.

156. Gulhas N, Topal S, Erdogan Kayhan G, Yucel A, Begec Z, Yologlu $S$, et al. Remifentanil without muscle relaxants for intubation in microlaryngoscopy: a double blind randomised clinical trial. Eur Rev Med Pharmacol Sci. 2013;17:1967-3.

157. Goudra BG, Singh PM. Propofol alternatives in gastrointestinal endoscopy anesthesia. Saudi J Anaesth. 2014;8:540-5.

158. Mali $S$, Anaphylaxis during the perioperative period. Anesth Essays Res. 2012;6:124-33.

159. Mertes PM, Lambert M, Gueant-Rodriguez RM, Aimone-Gastin I, Mouton-Faivre C, Moneret-Vautrin DA, et al. Perioperative anaphylaxis. Immunol Allergy Clin North Am. 2009;29:429-51.

\section{Esther Moreno}

\author{
Allergy Unit \\ Salamanca University Hospital-IBSAL \\ Antiguo Edificio Maternidad \\ Pso. San Vicente 58-182. Plta. Baja \\ 37007 Salamanca, Spain \\ E-mail: emrodilla@usal.es
}

